\title{
Recent advances in stimuli-responsive drug release and targeting concepts using mesoporous silica nanoparticles
}

\author{
Ghada G. Abdo ${ }^{1}$ Moustafa M. Zagho ${ }^{2} \cdot$ Ashraf Khalil $^{1}$ (D) \\ Received: 19 March 2020 / Accepted: 18 May 2020 / Published online: 18 June 2020 \\ (C) The Author(s) 2020
}

\begin{abstract}
Being a developed and promising approach, nanotechnology has attracted a lot of attention in biomedical and pharmaceutical therapy applications. Among nanostructured materials, mesoporous silica nanoparticles (MSNs) are effectively used as nanocarriers for drug delivery systems. MSNs can be tailored-designed by different synthetic techniques. Their morphological characteristics dictate the type of application of such materials. Recently, polymer-based materials have been employed to functionalize the MSNs surface. These modified nanocarriers are loaded with the drug and can unload their "cargo" upon exposure to either endogenous or exogenous types of stimuli. In this study, different targeting concepts, including passive, active, vascular, nuclear, and multistage targeting, are discussed.
\end{abstract}

Keywords Mesoporous silica nanoparticles · Drug delivery · Endogenous and exogenous stimuli · Anticancer drug delivery · Targeting

\section{Introduction}

Drug delivery relies on the presence of a "neutral" carrier that allows for a "load" drug to reach the desired target and release the cargo at the site. This approach enables remarkably reduced side-effects from the drug effect at "off-target" regions as well as protecting the drug from degradation or solubilizing prematurely. Well-designed and functionalized nanoparticles have proven to be excellent vehicles to carry this task [1]. Another critical factor in this process is the ability of the drug to be released upon exerting a stimulus upon the carrier nanoparticles to unload its cargo at the desired site. In this respect, stimuli-responsive polymers were introduced to carry on this task [2]. Important characteristics have to be realized in these polymeric systems such as receiving, transmitting the stimulus, and responding conveniently and efficiently. Two types of stimuli triggers are identified: those are endogenous and exogenous types. Endogenous biological triggers include $\mathrm{pH}$,

Ashraf Khalil

akhalil@qu.edu.qa

1 College of Pharmacy, QU Health, Qatar University, PO Box 2713, Doha, Qatar

2 School of Polymer Science and Engineering, University of Southern Mississippi, Hattiesburg, MS 39406, USA redox, glucose, and enzymatic systems. Endogenous type triggers anticipate the differences between the infected tissue and the microscopic environment surrounding this tissue in comparison to normal tissue physiology. Exogenous or external stimuli are, for instance, thermal, magnetic, and ultrasound effects. The latter have higher clinical applications because of the possible control over the carrier accumulation within certain positions around the targeted tissues and the precision in timing of the release of the load.

In the following sections, we will illustrate the synthetic strategies of mesoporous silica nanoparticles (MSNs) for different applications in drug delivery systems. The various techniques for applying exogenous and endogenous stimuli over MSNs for drug delivery will also be reviewed.

\section{Synthesis of mesoporous silica materials}

Mesoporous materials are defined by the international union of pure and applied chemistry (IUPAC) as those with pore size ranging between 2 and $50 \mathrm{~nm}$ arranged in an ordered pattern [3]. The first introduced mesoporous silica materials to the market were credited to those synthesized by Mobil Research and Development Corporation [4]. Those were designated commercial names as Mobil Crystalline Materials of Mobil Composition of Matter with an acronym of MCMs. 
The most popular ones are MCM-41 and MCM-48 and were introduced as catalysts. Extensive research was carried on these materials with efforts directed towards fine-tuning the structure of the resulting materials in terms of pore size. For example, MCM-48 nanoparticles $(90 \mathrm{~nm})$ demonstrated high permeability of encapsulated drug (resveratrol) compared to 150 and $300 \mathrm{~nm}$ ones [5]. On the other hand, the loading capacity of glucagon-like peptide-1 in dendritic silica nanoparticles (DSNPs) (pore size of $10 \mathrm{~nm}$ ) was much higher than MCM-41 with small pores [6]. The employment of surfactants with designated chain lengths and structures are the key players in controlling mesoporous characteristics. For instance, MCM-41 has been widely studied as a potential candidate for drug delivery applications and was synthesized using cationic surfactants as intercalation templates [4, 7]. Moreover, cationic surfactant (CTAB) was used as a structure-directing agent for designing a biphasic system composed of MSNs and calcium phosphate for bone-specific drug delivery (doxycycline hydrochloride) [8]. The researchers in Mobil used alkyl trimethyl ammonium halide-based surfactants as templates and tetra-ethoxy silicate (TEOS)-sodium silicate-silica-Ludox mixture as silicate source. Besides, MCM-41 had a hexagonal structure; MCM-48 had a cubic structure while MCM-50 had a lamella structure. Several synthesis conditions affected the properties of the resulting mesoporous materials. These include the concentration of precursors, the type of solvent/co-solvent used, the temperature and $\mathrm{pH}$ of the synthesis solution, the calcination temperature, the chain length of the surfactant used, electrolytes/solubilizing agents, and co-surfactants incorporation to the synthesis solution [7, 9-17].

Another category of mesoporous silica materials widely used in biomedical applications was synthesized by a group of scientists at the University of California, Santa Barbara, designated as SBA [18]. Relatively larger pores characterize SBA-based silica mesoporous materials compared to those of MCM- materials. The synthesis of SBA-materials relied on the use of non-ionic tri-block copolymers such as alkyl poly (ethylene oxide) and oligomer surfactants. The resulting mesoporous materials are SBA-11 with cubic structure, SBA-12 with a 3D hexagonal shape, SBA-15 with a hexagonal shape, and SBA-16 with cubic caged-structure. The designated form depends on the symmetry of the mesoporous structure and the polymers used [18].

Several mechanisms have been proposed for the preparation of these materials. Two mechanisms were initially suggested. Firstly, the silica framework is formed around preexisting liquid crystalline phases. Secondly, the addition of inorganic species affected the surfactant assembly and resulted in ordered arrays [19]. However, the first mechanism was not well-established because of the surfactant amount used in the synthesis solution is short from realizing the formation of liquid crystalline phase in aqueous media. Several other mechanisms were also cited, for instance, a mechanism described as "swelling-shrinking mechanism" was proposed and confirmed by time-resolved synchrotron small-angle X-ray scattering (SAXS) technique [20]. This mechanism is only valid when TEOS is the only precursor used and in the absence of any other ethanol-like solvent. Figure 1 showed the mechanism of formation of MCM-41 [22]. Figure 2 illustrated the mechanism of mesoporous silica nanoparticles (MSNs) according to the swelling-shrinking mechanism [22]. Comprehensive information can be found in the recently published review on the diverse routes of MSNs synthesis [23, 24]. Recently, novel virus-like MSNs consisted of nanospheres and peripheral perpendicular nanotubes were fabricated via a single micelle templating epitaxial growth strategy. These virus-like MSNs demonstrated superior cellular uptake property, good internalization ability, and prolonged blood circulation $(\mathrm{t} 1 / 2=2.16 \mathrm{~h})$ [25].

The more likely properties of MSNs that tailor the biomedical performance in terms of drug or gene loading and their release are particle size, pore size, and volume. For instance, relatively smaller particle sizes were obtained using some reagents, including alcohols, amines, inorganic bases, and inorganic salts [26-28]. Those agents affect the kinetics of hydrolysis and condensation reactions of the silica precursor. In 2014, a new generation of floating tablet-based MSNs was synthesized to enhance the delivery pattern of both hydrophobic (curcumin) and hydrophilic (captopril) drugs. The resultant tablets showed improved solubility for curcumin and prolonged release for captopril [29].

The pore size of the particles varied according to the chain length of the surfactants used. Thus, the applied surfactants with longer chain length resulted in the formation of larger pores [30]. Pore volumes, on the other hand, depended on the concentration of precursors and surfactants used. For example, the concentration of TEOS influenced the mesostructure ordering of the prepared MSNs [31]. Larger contents of TEOS resulted in more disordering in the mesostructure of particles, and insufficient contents hindered the mesoporous formation. The influence of the surfactant amount was discussed using cetyl ammonium bromide (CTAB) [21]. When CTAB was used with low concentrations, no micelles are formed, and no templates are available for the particle formation. Whereas, relatively high concentrations of CTAB resulted in disordered morphologies. Therefore, "moderate" concentrations of the surfactants are recommended for obtaining the desired mesoporous structure.

\section{Stimulus-responsive gatekeeping of functionalized MSNs}

Recently, designing a smart nanoparticle drug delivery system that responds to specific stimuli has gained a lot of attention

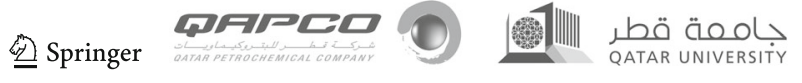


Fig. 1 Mechanism of formation of mesostructured surfactanttemplated inorganic materials for the synthesis of MCM-alike materials: (a) Liquid-crystal phase initiation; (b) Silicate anion initiation. (reprinted with permission from Elder [21]

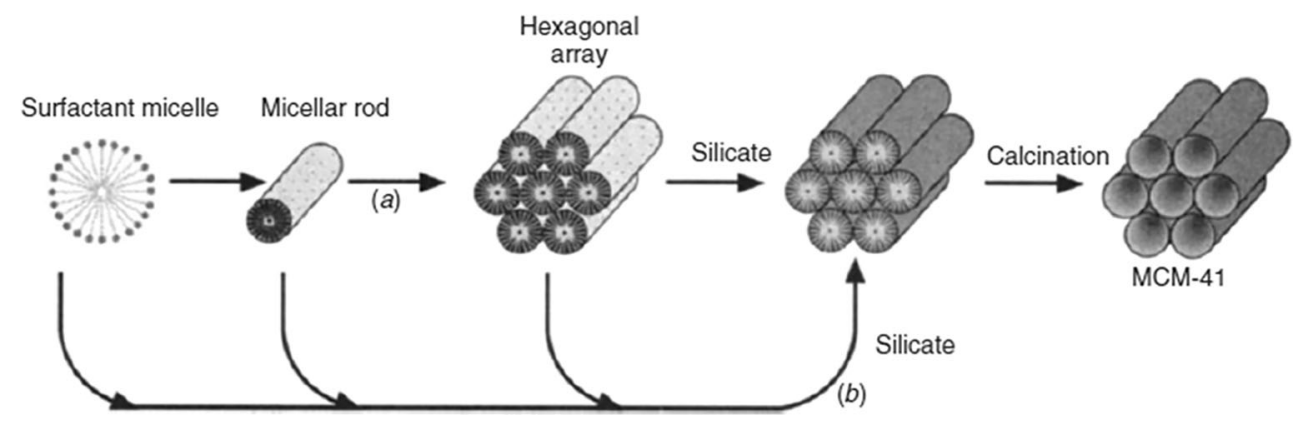

due to its tremendous promises in diagnostic as well as therapeutic application [32]. Two strategies are adopted in the synthesis of stimuli-responsive MSNs. In one approach, endogenous stimuli which are explicitly used for diseased tissue and proved to improve the drug action selectivity. It needs the addition of a suitable material to MSNs that respond to particular endogenous stimuli. The MSNs spontaneously enable the tumor-therapeutic selectivity and efficiency with bioresponsive therapeutic efficacy [33]. In the other strategy, it depends mainly on applying external physical stimuli to the desired tissue after administration of drug-loaded MSNs. Similarly, these applied exogenous stimuli lead to alteration of the MSNs structure and release of drug to the desired tissue [34]. Thus, researchers' effort is aimed towards applying a combination of several stimuli-responsive strategies to enhance targeting efficiency and avoid the premature drug release $[34,35]$.

\subsection{Exogenous stimuli-responsive drug delivery}

Exogenous-type stimuli are applicable by using an external factor such as temperature, electromagnetic and magnetic fields, and ultra-sound. Endogenous or exogenous stimuli are aimed to trigger the release of a given drug desirably at targeted locations inside the body. This approach is advantageous in targeting the specific delivery of a particular drug to its target site and limiting its side effects. The schematic diagram of Fig. 3 summarizes various exogenous and endogenous stimuli for drug delivery [36].

\subsubsection{Thermal-triggered drug delivery/release}

The strategy of this approach depends on changing the surrounding temperature around the particles loaded with the drug that resulted in triggering the pores around the surface of particles. Thermo-responsive drug delivery systems were widely implemented for anti-tumor treatment regimens [37]. This approach relies on coating or incorporating the MSNs with a thermo-responsive agent Fig. 4.

For example, MSNs were coated with organic/inorganic thermosensitive nanomaterials using reversible addition fragmentation transfer (RAFT) polymerization and click reaction [38]. Figure 5 demonstrates the coating of MSNs with thermoresponsive poly( $\mathrm{N}$-isopropyl acrylamide) (PNIPAM). In this mechanism, the drug is released when subjected to heating stimulus. Similar approaches could be applied to combine two exogenous stimuli, such as magnetic field and thermal change. A recent study by Rinaldi et al. suggested the use of super-magnetic iron oxide nanoparticles that release heat as a response to an alternating magnetic field. Consequently, molecular loading was released via Diels-Alder bond scission [39]. The nanocarriers were coated with poly (ethylene
Fig. 2 Schematic of the structural changes of CTAB micelles before and after TEOS addition. (1) Before the addition of TEOS; (2) After the addition of TEOS; (3) The silica monomers are progressively released into the aqueous solution; (4) Silica monomers gradually release from the core of micelles and form a silica shell around micelles; (5) Silica forms a strong framework, and particles and mesopores are formed. (Reprinted with permission from reference 20)

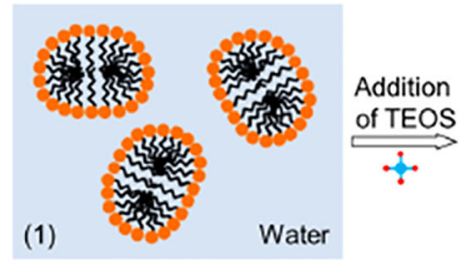

(2)
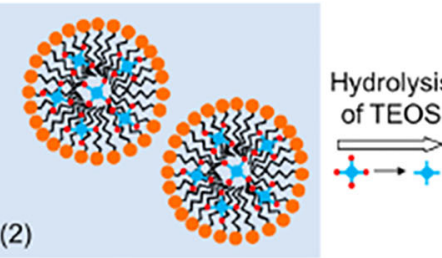

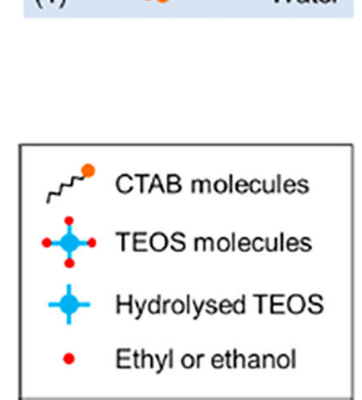

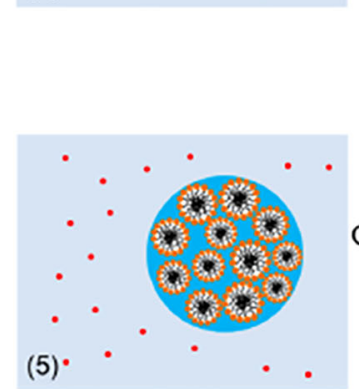

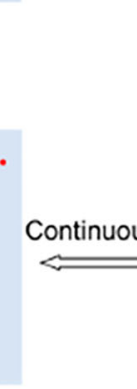

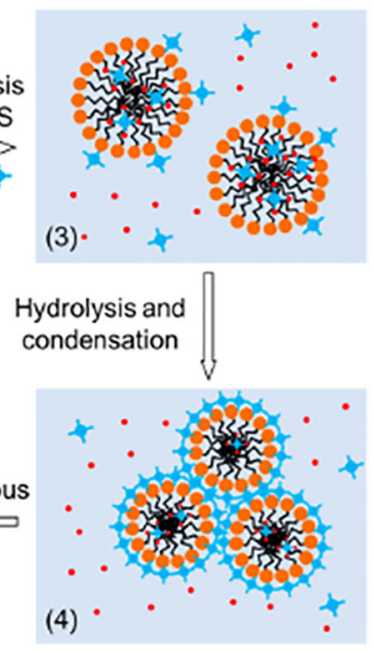

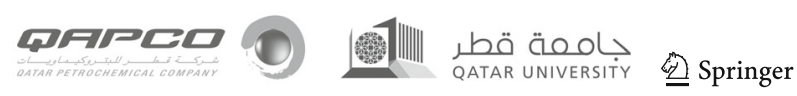


Fig. 3 Schematic diagram summarizing the various exogenous and endogenous stimuli for drug delivery (reprinted with permission from 36)

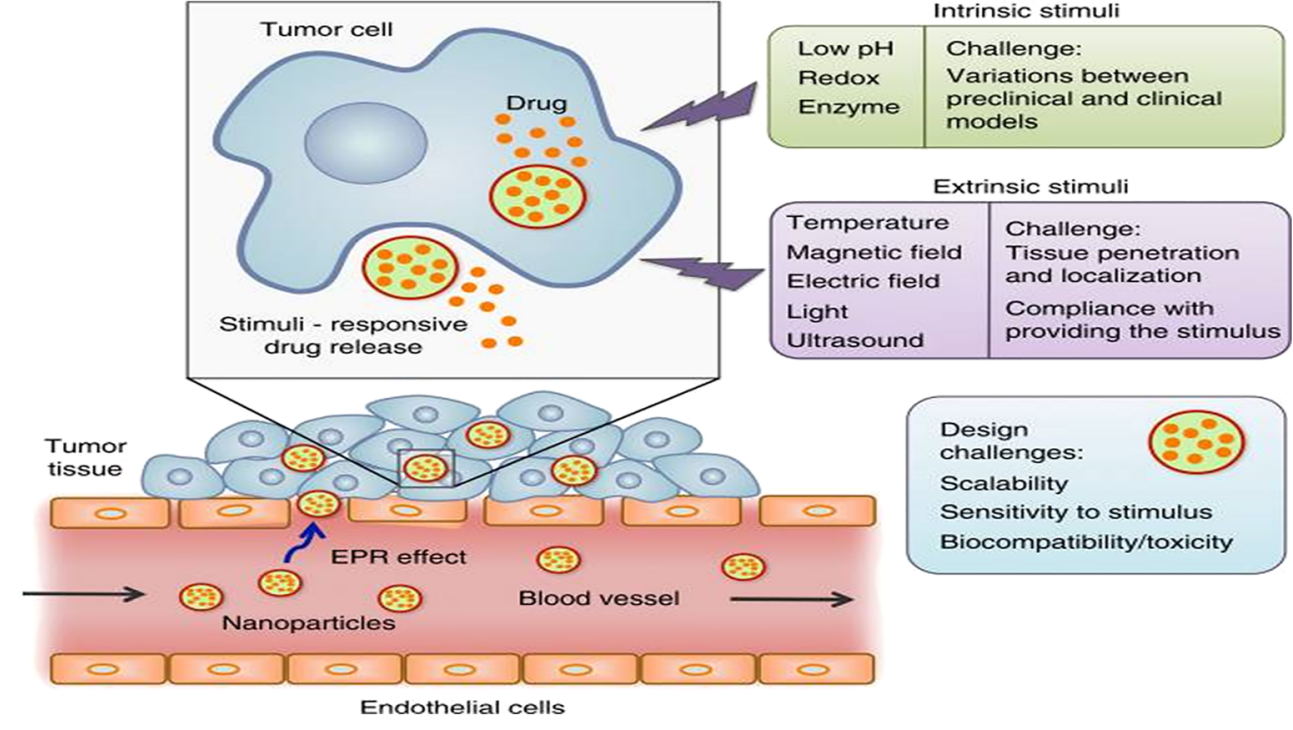

glycol)/poly (lactic acid) block copolymers. In their study, the authors reported that the release could be triggered multiple times using a magnetic field gradient to control the targeted regions for directive drug release spatially.

\subsubsection{Magnetic-triggered drug release}

Drug delivery based on magnetic trigger relies on releasing the magnetic and drug nanoparticles in response to the applied magnetic field. This performance ensures the directed delivery of magnetic nanoparticles to the targeted area in addition to controlling the drug release. Drug release in the response of the magnetic field relies on the ability of magnetic nanoparticles to produce thermal energy that induces morphological changes [40]. It was assumed that the magnetic core behaves like a hot spot that releases the drug without the need to elevate the global temperature [41] Fig. 6.
Iron oxide nanomaterials such as superparamagnetic nanoparticles were used extensively, replacing the MRI contrast agents [42]. Iron oxide nanoparticles have been linked to several ligands such as antibodies [43, 44], vitamins [45, 46], and polysaccharides [47]. In addition, a cyclic nine-amino acids peptide (Cys-Gly-Asn-Lys-Arg-Thr-Arg-Gly-Cys) (LyP-1) represented an excellent candidate for breast cancer, hepatocarcinoma, and atherosclerotic plaque therapies [46, 48]. The targeting of pancreatic cancer cells in vitro for diagnostic purposes was enhanced by using superparamagnetic mesoporous nanospheres anchored with lyp-1 ligand [49]. Doxorubicin has been loaded on graphene quantum dots (GQDs)-capped magnetic MSNs. These materials exhibited a synergistic effect against breast cancer 4T1 cells compared to chemohyperthermia and chemo-photothermal therapies. Under a magnetic field, the magnetic MSN/GQDs displayed heat liberation to the hyperthermia temperature [50]. Moreover, magnetic mesoporous silica microspheres with core-shell structure
Fig. 4 Schematic illustration of drug release from responsive MSNs triggered by temperature as an external stimulus
Temperature As External Stimuli

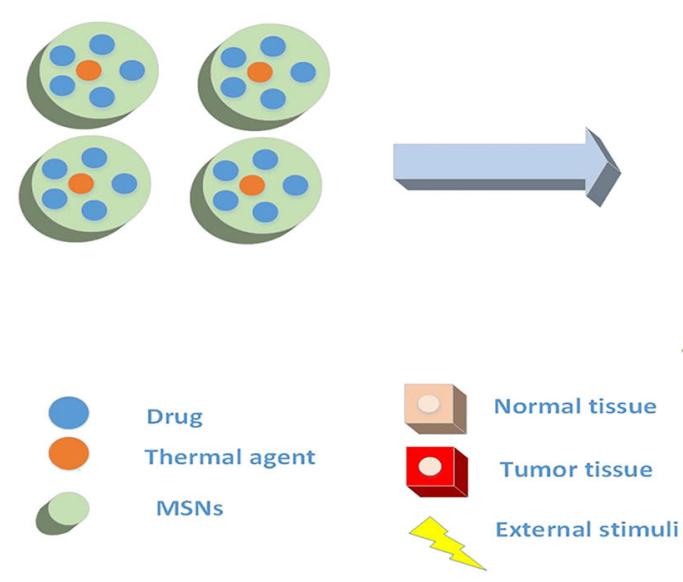

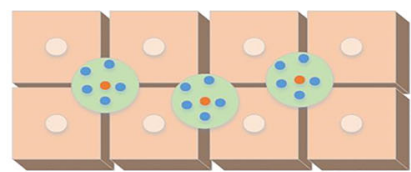

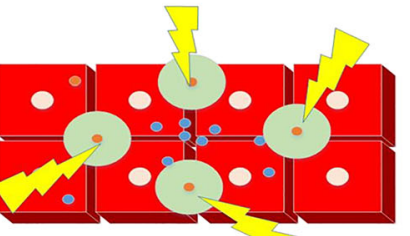

$\checkmark$ 
Fig. 5 Schematic diagram. Schematic illustrating the synthesis of MSNs coated with thermo-responsive PNIPAM brushes using RAFT polymerization and click chemistry (reprinted with permission from 38)
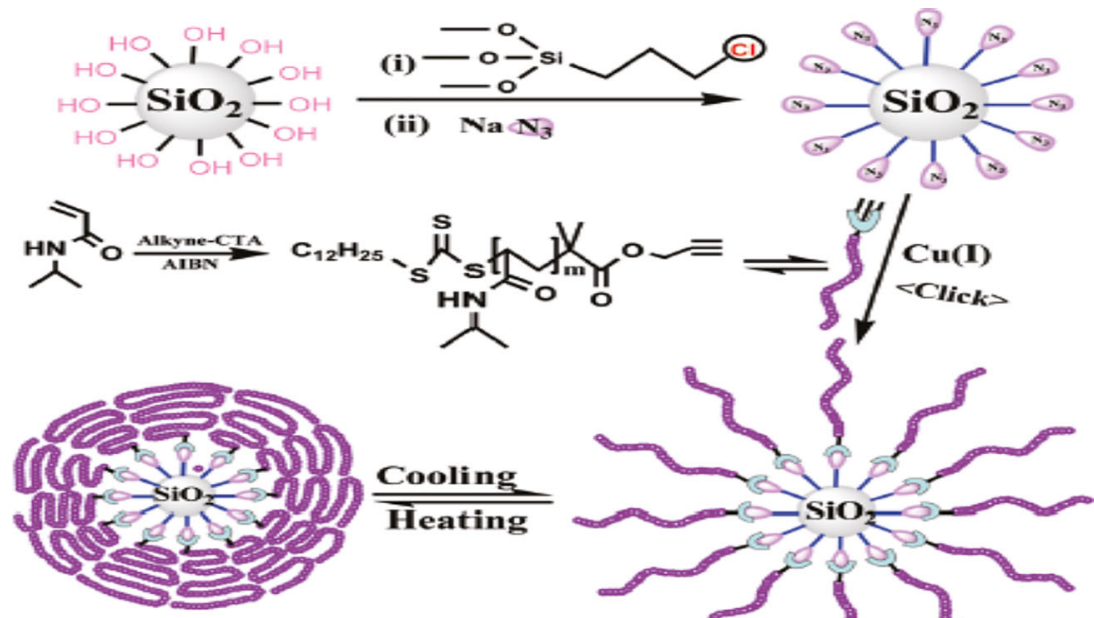
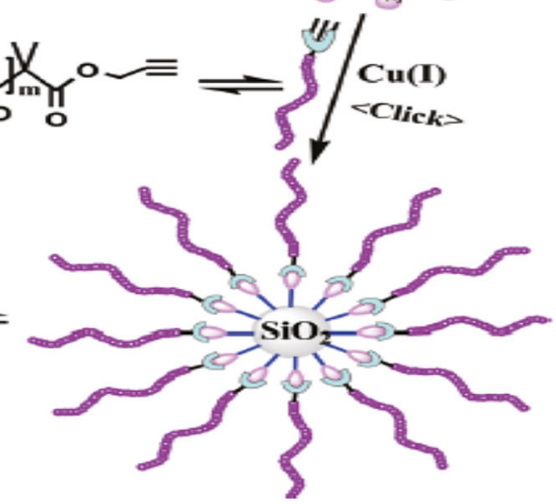

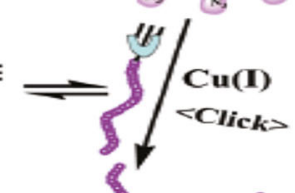

and large pores can be applied in bio-catalysis, bio-separation, and adsorption [51]. Surprisingly, Janßen et al. demonstrated that magnetic MSNs carriers did not accumulate on the magnetizable implant and area in orthopedics [52]. But instead, they were uptake and trapped in the lung, liver, and spleen of the mice with no significant pathomorphological alterations.

\subsubsection{Light-triggered drug release}

Activation delivery by light is a promising strategy due to its noninvasiveness property and remote control. It does not depend on changes in the chemical environment. The mechanism relies on conformational changes of the nanocarriers in response to light. Many light-triggered nanocarrier designs depend on releasing the drug from its cargo upon excitation by visible light or ultraviolet light. These nanocarriers proved to be suitable only for vitro studies owing to its fast reduction in density [53]. Previous reports demonstrated that nearinfrared gives maximum penetration, minimum absorbance, and more safety for tissues and organs than ultravioletvisible light $[54,55]$. Yang et al. fabricated smart and novel light stimulus MSN nanorods (MSNRs) doped with photosensitizer chlorin e6 (Ce6) for anticancer applications [56]. Doxorubicin release was achieved by coating MSNRs using bovine serum albumin through singlet oxygen-sensitive bis (alkylthio) alkene Bata linker (CMSNRs) and finally modified with polyethylene glycol. This carrier was activated via $660 \mathrm{~nm}$ with a low power density as low as $5 \mathrm{~mW} \mathrm{~cm}$ through SO-mediated cleavage of the Bata linker. In addition, they showed marked synergistic therapeutic effects in both in vivo and in vitro experiments.

Photodynamic therapy is an important therapeutic modality with high selectivity to the tumor and low invasiveness. A
Fig. 6 Schematic illustration of the mechanisms of drug release from MSNs triggered by a magnetic field and magnetic hyperthermia
1- Magnetic field directed targeting

\section{2-Magnetic hyperthermia}

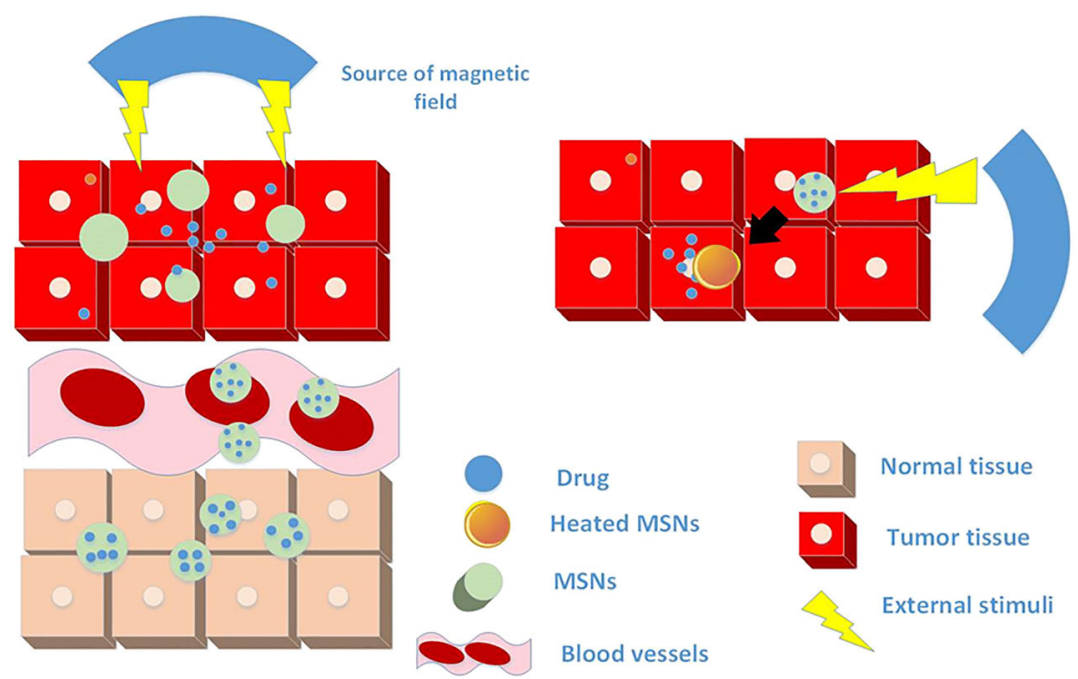


light source activates the tumor localized photosensitizer, and this property results in producing highly toxic ROS such as singlet oxygen that has proven to suppress the tumor with high efficiency and specificity with little side effects [57]. In 2015, Liu et al. synthesized double mesoporous silica-shelled UCNPs that can deliver both photosensitizer and bioreductive prodrug tirapazamine [58]. Upon excitation by laser at $980 \mathrm{~nm}$, a large amount of ROS was produced that eradicate the tumor and show the feasibility of NIR-triggered deep PDT by MSN-based therapeutic. Multifunctional nanoplatformbased MSN-coated gold nanorods were fabricated for PDT/ PTT synergistic therapy by Liu et al. [59]. MSN-based nanosensors were fabricated by incorporating a mesoporous silica shell with UCNP and oxygen indicator tris(4,7-diphenyl1,10phenanthroline) ruthenium (II) dichloride [60]. The mesoporous silica particles provide a large surface area that guaranteed high photosensitizer loading, while UCNP can upconvert NIR light into a light needed to activate these agents. These nanosensors showed marked selectivity and sensitivity for sensing the level of hypoxia in the cerebral anoxia model of zebrafish.

NIR-resonant nano-agents are widely employed in PTT in cancer. It depends on absorbing NIR and converting it to heat that eradicates the tumor cells [61, 62]. Novel NIR-induced DNA hybrid gated nanocarrier-based mesoporous coated with photothermal agent $\mathrm{Cu}_{1.8} \mathrm{~S}$ nanoparticles were fabricated by Sun et al. [63]. The produced photothermal effect was directed towards DNA double strands and causes its denaturation. Furthermore, it triggered the doxorubicin/curcumin release that causes marked synergistic impact in the anticancer therapy nanoplatform. Yang et al. enhanced the cellular uptake and anticancer targeting therapy by synthesizing NIR triggered $\mathrm{MoS}_{2}$ nanosheets coated MSNRs, modified with human serum albumin, and loaded with Ce6 [64]. In addition to NIR light-stimulated photodynamic therapy (PDT) and photothermal therapy (PTT), this carrier showed excellent biocompatibility, high contrast X-ray computed tomography imaging ability, in vivo fluorescence, and PDT synergistic effect from hyperthermia generation by $\mathrm{MOS}_{2}$.

Escoto et al. synthesized MSNs capped with gold nanoparticles for photo-triggered controlled drug release [65]. They found that the MSNs were efficiently linked with gold nanoparticles without the premature release of the paclitaxel into the normal healthy cells. A novel near-infrared laser-responsive mesoporous silica nanocarriers were composed of gold nanorods capped with reversible single-strand DNA. This DNA strand was controlled via a laser switcher that subsequently controls the release of drug from the nanocarrier. These nanocarriers demonstrated precise drug delivery at a specific time and to a particular region [54]. The isomerization of the photoactive sites controls the morphology of the photoactive molecules. Azobenzene is one of the most commonly used light-sensitive molecules due to its ability to undergo reversible photoisomerization under UV irradiation [66]. A novel strategy for NIR induced anticancer drug release was introduced by Liu et al. [67]. They fabricated azobenzeneinstalled MSNs with up-converting nanoparticles structure (UCNPs). Owing to light converting capabilities of UCNPs and trans-cis photoisomerization of azo molecules, at $980 \mathrm{~nm}$, the drug release was well-controlled and achieved better effective chemotherapy. Perylene-functionalized poly(dimethyl aminoethyl methacrylate) have been conjugated electrostatically to MSNs for controlled anticancer drug release. Perylene-functionalized poly(dimethyl aminoethyl methacrylate) were sensitive to visible light, and $\mathrm{pH}$ causing unsealing of the nanopores, and this enhanced the drug release because of synergistic effects [68].

\subsubsection{Ultrasound-triggered drug release}

Due to the fact of noninvasiveness and capability of penetration deeply in the tissue without damaging them, ultrasound is considered as one of the most promising triggers for drug release nanocarriers [69]. It has been reported that ultrasonic radiation improves the drug release from both biodegradable and non-biodegradable matrices. For instance, ultrasound triggered-MSNs were synthesized by grafting poly(2-(2methoxy ethoxy) ethyl methacrylate-co-2-tetrahydropyranyl methacrylate on its surface [70]. This copolymer consisted of both ultrasound and temperature triggered monomers. Upon ultrasound irradiation for $10 \mathrm{~min}$, the hydrophobicity of the polymer changes leading to opening the pores of MSNs and releasing the drug in a sustained pattern. Similarly, at $4 \mathrm{C}$, the conformation changes resulting in drug diffusion.

\subsection{Endogenous stimuli-triggered drug release}

Endogenous stimuli (biological stimuli) are the inherent environment of tumor tissues. For example, enzyme presence depends on acidic conditions and glucose concentration. In this section, we will discuss different responsive designs of nanocarriers to variations on $\mathrm{pH}$ value, enzyme, redox potential, and glucose.

\subsection{1 pH-triggered drug release}

The controlled drug released in the response of $\mathrm{pH}$ is one of the most exciting approaches. Drug release in the response of $\mathrm{pH}$ is a promising approach in cancer therapies because of the acidic microenvironment of the tumor cells, and $\mathrm{pH}$ change resulted from cancer cells internalization [71]. Generally, induced drug release from MSNs was accomplished by several strategies such as pH-cleavable linkers, acid-sensitive inorganic substances, polyelectrolyte, and supramolecular nanovalves. In 2009, pH-responsive mesoporous silica spheres 
were synthesized by coating MSNs with poly (methacrylic acid-co-vinyl triethoxylsilane) (PMV). The PMV shells manage the transfer of the drug molecules in response to $\mathrm{pH}$ change [72]. Furthermore, $\mathrm{pH}$-sensitive cleavable linkers were conjugated to MSN pores via hydrazine bonds for doxorubicin delivery (prodrug strategy). It was concluded that $\mathrm{pH}-$ directed drug delivery was highly effective with reduced doxorubicin systemic toxicity. Drug release in a sustained manner successfully reduced the unspecific secretion due to enzymatic hydrolysis. Moreover, this approach results in high drug loading, releasing efficiency, and cellular absorbance [73]. A polyacrylic acid grafted to MSNs was used to deliver and control the premature release of doxorubicin in bone cancer therapy [74]. Controlled $\mathrm{pH}$ triggered the release of drug molecules was achieved by acid-liable acetal linker and gold nanoparticles capped onto the MSNs. The release is based on acetal linkage cleavage at various $\mathrm{pH}$ values [75]. $\mathrm{ZnO}$ quantum dots were used to cap MSNs for effective intracellular dissolving in the acidic parts of cancer cells [76]. Recently, Nasrallah et al. designed core-shell magnetic mesoporous silica microspheres with a favorable $\mathrm{pH}$-responsive porous shell for drug delivery [77].

\subsubsection{Enzyme-triggered release}

Enzyme-responsive MSNs have also been widely investigated in the past decade. Hydrolyzed starch attached on the surface of MSNs was introduced as a potential carrier to release the entrapped drug in the presence of the appropriate enzyme. Different delivery profiles were obtained by changing the degree of starch hydrolyzation (i.e., associated with the length of the saccharides molecules) [78]. Lactose-capped MSNs were first introduced by Amorous and co-workers in 2009 [79]. They are selectively uncapped using b-d-galactosidase by the dissociation of a glycosidic bond and hydrolysis of the disaccharide lactose into the monosaccharides galactose and glucose.

Cancer is known as overexpressing and down in regulating various enzymes; hence, MSNs can be used as release triggers for this concept. MSNs act via ester, peptide, and urea bond cleavage. Enzymes such as esterase, elastase protease, and matrix metalloproteinases (MMPs) are used. MMPs, especially MMP2 and MMP9, are employed in almost all tumor cells and accompanied by cancer metastasis and angiogenesis [80, 81]. A case in point, MSNs were anchored to avidin via MMP9 to target overexpressing MMP9 cancer sites specifically. Successful MMP-9-triggered drug release was achieved in patient tumor cells and mouse lung cancer [82]. Cathepsin B is a type of protease that has widely applied in different enzyme-triggered drug release systems. MSNs-dependent cathepsin B were synthesized by Cheng et al. [83].

\subsubsection{Redox-triggered release}

Redox triggered carrier is considered as one of the most efficient tumor therapeutic approaches. This approach is based on the significant difference in redox potential between cancer and healthy tissues. The amount of glutathione (GSH) in tumor cells is threefold higher than that in normal cells [84]. The existence of GSH biological reducers efficiently cleave disulfide bond (S-S), permitting the use of redox-triggered drug release systems. The first redox-triggered drug delivery system was reported by Lai et al. [85]. They used CdS nanoparticles to seal the pore access of MSNs via a disulfide bond. Several inorganic nanoparticles served as nano valves to trap the drug inside the MSNs via covalent bonding with disulfide linkers such as zinc oxide [86], iron oxide [87], and CdS [85]. In another study, MSNs were synthesized with disulfide redox cleavable linkers on the surface and conjugated to beta-cyclodextrin. The MSNs successfully controlled the drug release via this linker [88].

Redox responsive MSNs were also functionalized with polymers such as polyethylene glycol (PEG) using a disulfide linker. The drug release was significantly increased with an elevated amount of glutathione; on the other hand, the sealed PEG in reduced GSH acted as gatekeeper [89, 90]. Furthermore, several supra-molecules were used as gatekeepers on MSNs. For instance, adamantane was grafted onto the nanopores of drug-loaded MSNs using a disulfide linker. The efficient internalization of drug-loaded MSNs into the cytoplasm of tumor cells was accomplished. The high amount of GSH removed the adamantane caps by breaking disulfide linkers [91, 92].

\subsubsection{Glucose-triggered release}

Glucose-triggered release systems have received a lot of attention recently in drug delivery strategies [93]. Glucoseresponsive MSNs are used in diabetes treatment by releasing a monitored amount of insulin in response to blood glucose concentration. For example, Zhao et al. synthesized boronic acid-functionalized MSNs for controlled delivery of both insulin and cyclic adenosine monophosphate (cAMp) in the response of glucose [93]. Gluconic acid-modified insulin was conjugated on the external surface of MSNs, which served as caps to trap the cAMP molecules inside the mesopores of MSNs. The presence of boronic acid resulted in the formation of more stable cyclic esters when exposed to glucose, leading to a controlled release of insulin and cAMP. Similarly, glucose-responsive alizarin functionalized MSNs integrated both drug and fluorescent real-time controlling issues [94]. Gluconate insulin using benzene-1,4-diboronic acid is integrated with the alizarin MSNs, which served as hypoglycemic drugs and gatekeepers. The glucose cleaved the boronate ester between alizarin and di-boronic acid resulting 
in pores opening and fluorescence disappearance. Recently, intestinal permeation and oral delivery of insulin $\left(10 \mathrm{U} \mathrm{Kg}^{-1}\right)$ have been significantly improved by incorporating anionic small silica nanoparticles $(<200 \mathrm{~nm})$ in both healthy and diabetic mice. The enhanced effect was nontoxic and reversible; in addition, the sustained hypoglycemic effect was achieved and lasted for a few hours [95].

\subsubsection{Adenosine triphosphate (ATP)-triggered release}

ATP is a multifunctional nucleotide responsible for providing energy for all biological processes. The ATP content in intracellular cytosols is higher than that in extracellular ones [96]. Therefore, ATP can be used to trigger the drug release inside the cytosol. Many reports confirmed the overexpression of tumor cells to ATP and the uncontrolled cancer growth [97, 98]. Graphene quantum dots were capped onto fluorescent MSNs through ATP aptamer for intracellular drug release [99]. The drug delivery was monitored via fluorescence resonance energy transfer, where under extracellular environment (low ATP concentration), the MSNs pores are closed, and the drug is trapped inside the MSNs. On the other hand, in the ATP-rich cytoplasm, the ATP aptamer changes its conformation resulting in shedding the graphene quantum dots from MSNs and releasing the drug in the tumor cells. Table 1 summarizes various stimuli systems employed for drug delivery using MSNs.

\section{Targeting approaches}

\subsection{Passive targeting}

The mechanism of passive targeting was discussed for the first time by Mastumura in 1986. It is mainly based on the leaky discontinuous microvasculature and defect of lymphatic functions of tumor tissues that result in improving permeability and retention (EPR) effect. Tumors exhibit rapid angiogenesis to maintain its proliferation by delivering the needed amount of oxygen and supplies [100]. This rapid angiogenesis results in apertures that enable the synthesized nanocarriers to enter the tumor cells and accumulate in it. However, this accumulation would take place if MSNs can escape from fast renal clearance and reticuloendothelial systems. This approach has been widely used to improve targeting using silica nanocarriers [101]. To illustrate, MSNs were synthesized by integrating functional nanoparticles in mesoporous shells included magnetic nanoparticles, and then attaching it onto the surface of MSNs. These MSNs successfully accessed the tumor sites of mice via passive targeting. In addition, these MSNs are applied in fabricating multimodal imaging probs for MR [102]. In the next sections, the different factors control the tissue accumulation, and cellular uptake of MSNs will be introduced.

\subsubsection{Size and shape}

Nanoparticle size determines circulation, distribution of MSNs, tissue accumulation, and cellular uptake. The agreed optimum nanoparticle size for biomedical applications is ranged from 10 to $300 \mathrm{~nm}$. However, maximum internalization was achieved from nanoparticles of 100-200 nm size by obtaining maximum accumulation in tumors via EPR [103, 104]. Small particles of $80 \mathrm{~nm}$ size have the longest mean residence time $(2 \mathrm{~h})$ and slow biodegradation. Nanoparticles larger than $400 \mathrm{~nm}$ display the inability to penetrate the tumor tissues and offering therapeutic effects. Spherical MSNs of 80-360 nm size are mainly distributed in the liver and spleen [105]. Lou et al. studied the cellular uptake of MSNs in Hela cells [106]. The cellular uptake was found to be size-dependent, and particle size of $50 \mathrm{~nm}$ is optimum to guarantee efficient cell internalization. In comparison, particles tend to agglomerate when particle size is less than $50 \mathrm{~nm}$, causing endocytosis lowering [107].

In addition, the shape of the nanoparticles represents an essential role in EPR-dependent tumor passive targeting. Gao et al. proposed the shape impact on cell internalization [108]. It was hypothesized that upon membrane stimulation, a diffusive ambulant receptor wraps the ligand coated spherical particles. Generally, spherical nanoparticles have been widely used in many biomedical applications because of its simple fabrication method and shorter wrapping time that resulted in faster internalization [108]. The shape influence of silica nanoparticles on cell internalization efficiency was discussed for the first time by Trewyn et al. [109]. They designed spherical and tube-like MSNs labeled with fluorescein and tested them in cancer cell lines and noncancerous. The results demonstrated that cellular uptake and endocytosis are morphology dependent. Similarly, spherical MSNs demonstrated faster internalization rates in Chinese hamster ovarian than tube-like ones [109]. Aspect ratios (ARs) showed a positive association with endocytosis rates and accumulation of MSNs in the cell [110]. This observation was also confirmed by designing three MSNs with different aspects ratios $(1,2$, and 4) while maintaining the diameter, chemical structure, and surface charge unchanged. These MSNs offered different internalization efficiency in A375 human melanoma. However, particles with larger ARs provided higher cellular uptake [110]. Another report demonstrated that rod-like MSNs with ARs of 2.12.5 displayed faster internalization and more efficient penetration than the spherical ones [111]. Short rod-like MSNs existed mainly in the liver with a rapid clearance rate while the long ones distributed in the spleen [112]. Based on these research findings, it is hard to conclude the most suitable MSNs shape needed for passive targeting systems. 
Table 1 Reviewed stimuli employed for drug delivery using MSNs

\begin{tabular}{|c|c|c|}
\hline Stimuli & Mechanisms & Reference \\
\hline \multicolumn{3}{|c|}{ 1. External stimuli } \\
\hline \multirow[t]{4}{*}{ Temperature } & MSNs coating with PNIPAM & {$[38]$} \\
\hline & Dual responsive MSNs & {$[39]$} \\
\hline & (Magnetic field + temperature) & \\
\hline & $\begin{array}{l}\text { Increase of temperature under the action of an alternating magnetic field } \\
\text { Superparamagnetic iron core in MSNs }\end{array}$ & {$[40-42,51]$} \\
\hline \multirow{2}{*}{$\begin{array}{l}\text { Magnetic } \\
\text { field }\end{array}$} & Magnetic MSNs+ cyclic amino acid lyp & {$[46,48,49]$} \\
\hline & Magnetic MSNs + quantum dots as a cap & {$[50]$} \\
\hline \multirow[t]{4}{*}{ Light } & NIR & {$[54,61-64,67]$} \\
\hline & MSNs capped with gold nanoparticles & {$[59,65]$} \\
\hline & Activated via photosensitizer agent & {$[56,58,60]$} \\
\hline & $\begin{array}{l}\text { Dual responsive MSNs (NIR }+\mathrm{pH} \text { ) Perylene-functionalized poly } \\
\text { (dimethyl-aminoethyl methacrylates) }\end{array}$ & {$[68]$} \\
\hline Ultrasound & $\begin{array}{l}\text {-MSNs were synthesized by grafting } 2 \text {-(2methixyethoxy) ethyl } \\
\text { methacrylate co-tetrahydro-pyranyl methacrylate on its surface }\end{array}$ & {$[70]$} \\
\hline \multicolumn{3}{|c|}{ 2. Internal stimuli } \\
\hline \multirow[t]{5}{*}{$\mathrm{pH}$} & $\begin{array}{l}\text { PH-responsive mesoporous silica spheres, accomplished by coating with } \\
\text { poly (methacrylic acid-co-vinyl triethoxylsilane) (PMV). }\end{array}$ & {$[72]$} \\
\hline & Conjugating $\mathrm{pH}$-sensitive cleavable linker to MSN pores via hydrazine. & {$[73]$} \\
\hline & A poly acrylic acid grafted to MSNs & {$[74]$} \\
\hline & Acid- liable acetal linker and gold nanoparticles capped onto the MSN. & {$[75]$} \\
\hline & MSNs capped with $\mathrm{ZnO}$ (Acidic cleavage) & {$[76]$} \\
\hline \multirow[t]{4}{*}{ Enzyme } & Hydrolyzed starch attached to MSNs surface & {$[78]$} \\
\hline & Lactose capped MSNs & [79] \\
\hline & $\begin{array}{l}\text { MSNs anchored to avidin via MMP9, specifically target over } \\
\text { expressing-MMP9 cancer sites }\end{array}$ & {$[82]$} \\
\hline & MSN-dependent cathepsin B & {$[83]$} \\
\hline Redox & S-S cleavage disassembly & [89-92] \\
\hline \multirow{3}{*}{$\begin{array}{l}\text { Small } \\
\quad \text { molecules }\end{array}$} & Glucose concentration & {$[93,94]$} \\
\hline & Anionic small silica nanoparticles (oral insulin delivery) & {$[95]$} \\
\hline & Competitive binding in presence of ATP & {$[99]$} \\
\hline
\end{tabular}

$A T P$, denosine triphosphate; $p N I P A M$, poly(N-isopropylacrylamide); $N I R$, near infrared radiation; $Z n O$, zinc oxide

\subsubsection{Surface}

MSN surface plays a vital role in cell internalization, biodistribution, cell binding, and blood circulation time. MSNs are well-known to acquire large surface area and pore volume. The challenges are faced in designing MSNs with appropriate functionalization and charges to ensure the proper interaction with the targeted physiological cells [113]. Interaction between red blood cells (RBCs) and silica nanoparticles resulted in hemolysis. The negative charge of the silanol group results in strong affinity and binding to RBCs. These underlying phenomena affect the internalization of MSNs in the tumor tissues and compromise the efficiency of passive targeting. However, this behavior could be modified by attaching an organic constituent to MSNs [114, 115]. Additionally, the resulted opsonization from nonspecific adsorptions of plasma proteins on the MSNs surface affects the passive targeting. This adsorption creates protein corona that rapidly cleared via RES system [116]. PEGylation is a common strategy used to overcome these phenomena. PEGylation can be achieved by surface functionalization of MSNs using polyethylene glycols (PEGs) [117]. This functionalization process reduces the protein binding via electrostatic repulsion and steric hindrance effects. The optimum PEG molecular weight for this purpose is $10,000-20,000 \mathrm{~g} / \mathrm{mol}$. Moreover, PEGylated MSNs displayed a significant reduction in hemolysis events [118]. Recently, the influence of surface modification of MSNs using lipids and PEGs on mesenchymal stem cell internalization was investigated [119]. This modification resulted in improving internalization capacity 17 times higher (>80\%) than the unmodified ones. On the other hand, the protein resistance character was reduced at temperatures higher than $35^{\circ} \mathrm{C}$. Moreover, the pharmacokinetics property of PEGylated MSNs was altered over time with repeated 
injections in animals [120]. It was emphasized that PEGs produce anti-PEG IgM that resulted in faster blood elimination [120]. Recently, the conjugation of MSNs with zwitterionic copolymers resulted in enhancing the stability and increasing blood circulation half time [121].. Lipid coating has also been applied as an alternative strategy to escape from RES clearance [122]. The charge on the surface of the nanoparticles plays a significant role in passive targeting. Since the cell membranes are negatively charged, positively charged surface nanocarriers offer higher cell uptake than the negatively or neutrally charged ones. The final surface charge of nanocarriers tends to be negative due to plasma coating [123]. Surface functionalization of MSNs with contrast agent indocyanine green (ICG) was investigated for photoacoustic imaging to overcome ICG serum protein binding problems and rapid clearance [124]. $\mathrm{NH}_{2}$ modification of MSNs displayed higher ICG loading ability (16.5 wt $\%$ ) compared to $\mathrm{PO}_{3}$ modified MSNs (3.5 wt \%). Furthermore, $\mathrm{NH}_{2} \mathrm{MSNs}$ showed 1.34-fold PA signal improvement compared to ICG alone. MSNs modification with silanes having $\mathrm{NH}_{2}$ or $\mathrm{PO}_{3}$ groups resulted in improving the solubility of Vorinostat for the treatment of cutaneous $\mathrm{T}$ cell lymphoma (3.9-fold and 4.3fold respectively, compared to the free drug) [125]. Furthermore, resveratrol was efficiently encapsulated with $\mathrm{NH}_{2}$ and $\mathrm{PO}_{3}$ modified MSNs. These MSNs showed dosedependent sensitization of docetaxel for the hypoxic condition in prostate cancer [126].

\subsection{Active targeting}

Active targeting relies on the interaction between cancer cells and drug loading cargos. Functionalizing the surface of MSNs with a specific ligand is necessary for the active targeting of cancer cells. Macromolecules, antibodies, nucleic acids, vitamins, sugars, and peptides are examples of ligands that applied to anchor the MSNs for successful active targeting. This strategy depends on the ligand affinity to the cancer cells overexpressed receptors [127]. In general, the site-specific active targeting strategies can be classified into a tumor cell, vascular, and subcellular organelles targeting (Fig. 7).

\subsubsection{Surface functionalization of MSNs for cancer applications}

\subsubsection{Functionalization by folic acid}

Targeting using folic acid has been widely used in many in vitro studies, yet there are limited reports discussed in vivo studies. To illustrate, docetaxel-loaded folic acid MSNs showed improved cellular uptake, apoptotic, and anticancer activity against breast cancer MCF-7 cells. The vivo fluorescent imaging revealed the accumulation of folic acid MSNs in the kidney of healthy mice [129]. Other conducted studies compared the performance of camptothecin-loaded MSNs to folic acid functionalized camptothecin/MSNs in terms of xenograft pancreatic cancer suppression. Folic acidfunctionalized camptothecin/MSNs provided excellent biocompatibility and significant inhibition of tumor growth [130]. Naturally originated anticancer prodrug colchicine, quercetin, and curcumin have been loaded on folic acid conjugated MSNs. These novel MSNs were successfully employed in targeting vitro hepatocellular cancer cells (HeLa). Additionally, they showed marked enhanced targeting to liver cancer cells [131].

\subsubsection{Functionalization by mannose}

Another promising approach is the functionalization of MSNs using mannose. Anchoring mannose to MSNs with photosensitizer showed remarkable targeting breast cancer cells (MDA-MB-231). Mannose exhibited high photodynamic efficiency on breast cancer cells [132]. Cancer cells were demonstrated to have a high affinity to glycosylated moieties. The galactose-conjugated fluorescent nanoparticles were designed using lactobionic acid (LA) through EDAC linkage. They are highly selective to liver cancer cells without harming the normal ones [133]. Besides, colorectal cancer cells can be targeted using galactose-functionalized camptothecin/ porphyrin-loaded MSNs. This synergistic combination of photodynamic therapy (porphyrin) and targeted drug delivery (camptothecin) enhanced the internalization of MSNs in the endosome [134].

\subsubsection{Functionalization by monoclonal antibody}

The monoclonal antibody can target cell receptor antigens that are overexpressed on cancer cells more than that overexpressed on the normal ones. For this purpose, a monoclonal antibody $(\mathrm{mAb})$ functionalized MSNs containing green fluorescent dye were prepared by grafting Herceptin to MSNs outer surface for selective targeting epidermal growth factor receptor HER2/neu glycoprotein. The synthesized nanocomposites showed high internalization in breast cancer cells as well as selective targeting by Herceptin [135]. Epithelial cell adhesion molecule antibody (EpCAM) is a transmembrane glycoprotein, which is overexpressed in many cancer cells and cancer stem cells. EpCAM acts as an efficient preventive of metastatic cancer by targeting the circulating tumor cell and inhibiting the contact-invasion to vascular intima [136]. Interestingly, long-circulating (EpCAM) grafted to mifepristone (MIF)-loaded MSNs prevented lung metastasis cascade in the mouse. This system selectively targets colorectal cancer cells in both cell and blood mediums [137]. Similarly, doxorubicin-loaded MSNs anchored to EpCAM-aptamer were efficiently delivered to colon EpCAM overexpressing SW620 tumor cells. This unique design exhibit a controlled 
Fig. 7 Schematic diagram illustrating active targeting by MSNs. (1) Cancer vascular targeting. (2) Cancer cell targeting. (3) Nuclear targeting (reprinted with permission from 128)

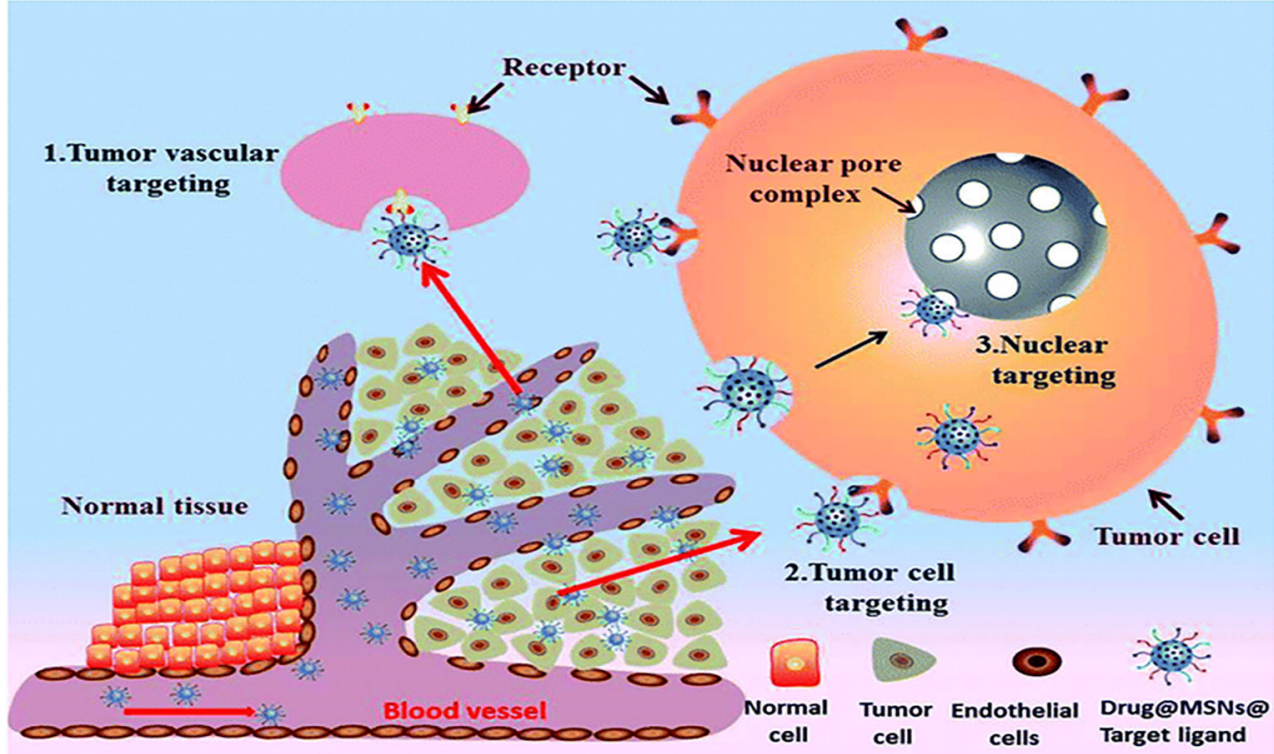

release pattern, and the drug release was favored in acidic medium ( $\mathrm{pH}$ 5.5) resulted in improving targeted therapy and reducing side effects [138]. Mucin-1 is also a transmembrane glycoprotein that is overexpressed nearly in all epithelial cancer cells. Near-infrared MSNs were linked to the mucin-1 antibody successfully to detect primary breast carcinoma and to track breast cancer cell metastases in transgenic mouse model [139]. Recently, targeting cancer stem cells have grabbed researchers' interest in initiating and maintaining tumor proliferation. For instance, daunorubicin-loaded MSNs were conjugated to succinic anhydride capped with the antiB220 antibody for targeting leukemia stem cells. Also, incorporating these MSNs markedly retarded leukemia proliferation in mice model [140].

\subsubsection{Functionalization by DNA aptamer}

Recently, the functionalization using signal responsive DNA switches has gained a lot of attention, making them valuable alternatives to antibodies and peptides. Various triggers can be used to stimulate the DNA switches such as light, metal ions, $\mathrm{pH}$, and aptamer substrate complexes [141]. The release of the substrate entrapped in MSNs is controlled by tailoring nucleic acid tags. In normal cases, this tag inhibits the release of the substrate from the MSN pores. On the other hand, the presence of a biomarker induces a catalytic decomposition resulting in nucleic acid rearrangement and pore opening, permitting the substrate release [142]. Nucleic acid cap identifies molecular biomarkers via aptamer substrate complexes [142]. Mucin-1 is overexpressed in about $90 \%$ of breast cancer therapies. Safranin O-loaded MSNs have been capped with negatively charged aptamers for efficient internalization in MDAMB-231 breast cancer cells and controlled substrate release.
Furthermore, the MSNs were radiolabeled with ${ }^{99 \mathrm{~m}} \mathrm{TC}$ for improved carcinoma targeting [143].

\subsubsection{Functionalization by hyaluronic acid}

Hyaluronic acid (HA) is the main component of the extracellular matrix of the biocompatible glycosaminoglycan needed for growth and maintaining tissue stability. Many tumor cells, such as CD44, have been reported to have overexpression to HA. Besides, HA exhibits multifunctional moieties available for binding several anticancer drugs and nanocarriers. Thus, HA functionalized MSNs are widely used in various pharmaceutical applications [144]. Colon cancer cell (HCT-116) surface exhibits CD-44 overexpression. Therefore, it has been targeted using HA-conjugated doxorubicin-loaded MSNs. High apoptosis to HCT-116 and enhanced internalization in the tumor cells was achieved [145]. Lee et al. investigated for the first time the antiviral characteristics of functionalized MSNs for herpes simplex virus infection [146]. They demonstrated that glycosaminoglycans mimetic functionalized MSNs act as viral binding/entry inhibitors that prevent the cells from being infected by HSV-1 and HSV-2.

\subsubsection{Functionalization by peptides}

The integrin receptor is overexpressed in various cancer cells, and this receptor could be selectively targeted using tripeptides (arginine-glycine-aspartic acid) (RGD). For instance, MSNs were designed for NIR-responsive drug delivery and chemo/photothermal therapy. RGD sequences were anchored on the doxorubicin-loaded MSNs surface, and they showed efficient internalization in tumor cells through receptor-mediated uptake and high stability in the bloodstream [147]. RGD anchored to MS-encapsulated gold 
nanorods offered an improved uptake in breast carcinoma via alpha $\mathrm{V}$ beta 3 integrin, and they significantly enhanced the radio-sensitization of triple-negative breast cancer cells [148]. ADDA-TCPP amphiphile peptides were immobilized onto doxorubicin-loaded MSNs. These MSNs blocked the premature release of doxorubicin via the hydrophobic interactions between alkyl sequences of ADDA-TCPP. Additionally, the release of the drug was triggered by glutathione [149]. Moreover, MSNs showed promising potential for guided tissue regeneration [150]. Xu et al. fabricated MSNs by coaxial electrospinning, where both growth and antibiotic factors were loaded in the core and shell of MSNs, respectively. These MSNs demonstrated sustained release patterns of the growth factor besides efficient ontogenetic regeneration abilities towards bone marrow stromal cells (BMSCs) as well as excellent antibacterial properties.

\subsection{Vascular targeting}

Angiogenesis (formation of new blood vessels) is necessary for the growth and metastasis of cancer cells [151]. Therefore, vascular targeting is considered as a promising alternative for targeting solid tumors. This strategy is based on indirect targeting carcinomas through destructing endothelial cells of tumor vessels to cease their needed oxygen and nutrients [152]. Vascular targeting is more favored than other approaches as cellular internalization in tumors and extravasation from blood vessels are not required [153]. Therefore, many challenges can be overcome using this strategy, such as tumor heterogeneity and poor delivery. Although the concept of vascular targeting was introduced in the 1920s [154], but the first successful vivo cancer vascular targeting was achieved by Burrows and Thorpe in 1993 [155]. This approach is based on conjugating the nanocarriers with vasculature-targeting ligands such as vascular endothelial growth factor (VEGF) and arginine glycine aspartic acid (RGD) peptides. In addition, VEGFRtargeted MSNs anchored to Cu-NOTA/PEG-VEGF were synthesized [154]. These MSNs displayed threefold improvement in terms of cancer accumulation [156]. Similarly, conjugating ursolic acid and VEGF-targeted siRNA to MSNs anchored with folic acid were examined on folate receptor overexpressing HeLa cells and folate receptor-negative HepG2. They combined active and passive targeting concepts and achieved a significant improvement in targeting efficiency. Furthermore, the stability of VEGF-targeted siRNA was enhanced using folic acid ligand [157]. In summary, incorporating suitable ligands results in improving targeting efficiency and overcoming the existing challenges.

\subsection{Nuclear targeting}

The concept of nuclear targeting using MSNs has been introduced by Pan et al. [158]. MSNs were conjugated to nuclear localization signal TAT peptides. The MSNs-TAT systems of 50-nm diameter were able to target the nucleus and accumulate doxorubicin in the tumor nucleus. This approach has been developed to overwhelm many challenges. For instance, several free anticancer drugs provided a suppressed therapeutic efficiency after reaching the nucleus owing to many physiological barriers [159]. The nuclear-targeted strategy is adhered via anchoring MSNs surface to nuclear localization signals such as gold nanoparticles [160,161], magnetic nanoparticles [162], and quantum dots [163]. Recently, this approach has been widely applied in gene therapy [164]. To illustrate, functionalized MSNs were employed in codelivery of osteogenic genes and drugs. This dual system showed synergistic improvement in the osteogenic impact of stem cells. Moreover, doxorubicin delivery via nuclear targeted MSNs overcome the multidrug-resistant problem (MDR) by upregulating the genes responsible for the apoptosis of multidrug-resistant cells. Additionally, this approach accomplished downregulated expression of the apoptosis-suppressing gene bcl-2 and prevented the activation of the DNS repair system for improved MDR cells apoptosis [165].

\subsection{Multistage targeting}

This approach was recently developed due to unsatisfactory therapeutic outcomes resulted from single targeting ones (cancer cells, nuclei, or endothelial cells). This novel strategy can be achieved via conjugating multiple ligands on the surface of MSNs exhibiting high selectivity and affinity to different tumor types. This design results in targeting various disease sites, a high therapeutic index, and reduced systemic side effects [166]. Multistage ongoing targeting approach relies on synthesizing magnetic MSNs for efficient accumulation in the cancer tissues, then conjugating TAT peptide to MSNs surface for nuclear targeting, and finally attaching chargeconversional polymer originated from folate anchored chitosan. This smart approach causes accumulation of MSNs in the tumor using magnetic nanoparticles, enhances cellular uptake via folate receptor endocytosis, and targets cell nucleus using TAT peptides [167]. Pan et al. have extrapolated the multistage targeting approach to vivo application. MSNs were coupled with RGD peptide that resulted in efficiently targeting the tumor vasculature and cell membrane [168]. Additionally, TAT peptides were used for nuclear targeting signals that guaranteed efficient nuclear uptake. Significant enhancement in therapeutic efficacy and tumor suppression $(98.6 \%)$ were noticed as a result of sequential vascular-to-cell nucleartargeted drug delivery. Naz et al. developed novel multistage-targeted anticancer MSNs that are capable of targeting both CD44 and mitochondria [169]. Utilizing triphenylphosphine (TPP) as a mitochondrial targeting agent was anchored onto the surface of MSNs. Doxorubicin was loaded in MSNS, and HA was capped with MSNs (as a

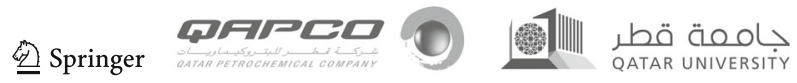


tumor-targeting agent). CD44 receptor of tumor cells uptake these MSNs composite, then accumulated in mitochondria due to the presence of the TPP compound. HAase enzyme overexpression in cancer cells caused degradation of HA and release of doxorubicin and resulted in efficient eradication of cancer cells. Hollow MSNs anchored with tLyp-1 peptide (tHMSN) for dual-targeting drug delivery to cancer cells, and angiogenic blood vessels were synthesized by Liu et al. [170]. Doxorubicin loaded on tHMSN showed a high inhibitory effect on MDA-MB-231 cells and HUVECs in vitro. In another study, cell-targeting agents, folic acid, dexamethasone, and nucleus targeting agent (TAT) were coupled in $40 \mathrm{~nm}$ MSNs [171]. These cell-nucleus sequential targeting-based MSNs improved the inhibition efficacy of doxorubicin on Hela cells and decreased the toxic side effects on normal cells.

\section{Conclusion}

It is evident from ineffective conventional therapies that there is a desperate need for distinct and promising therapies. As extensively discussed, MSN-based nanostructure technology has the potential to play critical functions in cancer treatment. MSNs have promising potential in drug delivery due to its unique physical-chemical characteristics. Through functionalization with various groups and molecules on MSNs surface, stimuli-responsive and targeting approaches have been proved to provide unprecedented opportunities and advances for novel theranostic modalities. However, despite the extraordinary breakthrough that has been made to modify and enhance MSNs based drug loading and release, still, using MSNs in clinical applications require more efforts to translate these preclinical findings into the clinic. Currently, the most significant studies are achieved as in vitro experiments (cell culture), while tissue penetration is not demonstrated yet. Such results may not mimic the in vivo environment and described critical difficulties in translating these MSNs based nano-systems in the clinical trials. Furthermore, it is widely noticed that very few articles discussed the fate and the clearance pathways of these nanomaterials that may be accumulated and caused massive toxicity. Therefore, more preclinical in vivo animal studies need to be conducted to demonstrate various unknown systemic aspects of these nanocarriers, such as processing, accumulation, and elimination in the living organisms.

Nanostructured materials, namely mesoporous silica nanoparticles, represent a promising candidate in drug delivery applications. In this review, we highlighted the recent insights in the functionalization of MSNs for cancer therapy applications, including stimuli triggered drug release and cancertargeted delivery. We also reviewed the current designs applied for successful targeting using MSNs. Prospective investigations are still needed to ensure the introduction of MSN-based drug delivery systems to the clinical market.

Funding Information This work was supported by the High Impact-Fund Program Grant QUHI-CAS-19/20-1 from Qatar University. Open Access funding provided by the Qatar National Library, Doha, Qatar

\section{Compliance with ethical standards}

Conflict of interest The authors declare that they have no conflict of interest.

Open Access This article is licensed under a Creative Commons Attribution 4.0 International License, which permits use, sharing, adaptation, distribution and reproduction in any medium or format, as long as you give appropriate credit to the original author(s) and the source, provide a link to the Creative Commons licence, and indicate if changes were made. The images or other third party material in this article are included in the article's Creative Commons licence, unless indicated otherwise in a credit line to the material. If material is not included in the article's Creative Commons licence and your intended use is not permitted by statutory regulation or exceeds the permitted use, you will need to obtain permission directly from the copyright holder. To view a copy of this licence, visit http://creativecommons.org/licenses/by/4.0/.

\section{References}

1. H. Jahangirian, E.G. Lemraski, T.J. Webster, R. RafieeMoghaddam, Y. Abdollahi, A review of drug delivery systems based on nanotechnology and green chemistry: green nanomedicine. Int. J. Nanomedicine 12, 2957-2978 (2017). https://doi.org/10.2147/IJN.S127683

2. N.V. Rao, H. Ko, J. Lee, J.H. Park, Recent progress and advances in stimuli-responsive polymers for cancer therapy. Front Bioeng Biotechnol 6 (2018). https://doi.org/10.3389/fbioe.2018.00110

3. A.D. McNaught, A. Wilkinson, Mesopore in Catalysis. In IUPAC Compendium of Chemical Terminology (IUPAC, Research Triagle Park, NC, 2008). https://doi.org/10.1351/goldbook. $\mathrm{m} 03853$

4. C.T. Kresge, M.E. Leonowicz, W.J. Roth, J.C. Vartuli, J.S. Beck, Ordered mesoporous molecular sieves synthesized by a liquidcrystal template mechanism. Nature 359(6397), 710-712 (1992). https://doi.org/10.1038/359710a0

5. E. Juère, J. Florek, M. Bouchoucha, S. Jambhrunkar, K.Y. Wong, A. Popat, F. Kleitz, In vitro dissolution, cellular membrane permeability, and anti-inflammatory response of resveratrolencapsulated mesoporous silica nanoparticles. Mol. Pharm. 14(12), 4431-4441 (2017). https://doi.org/10.1021/acs. molpharmaceut.7b00529

6. Abeer, M. M.; Meka, A. K.; Pujara, N.; Kumeria, T.; Strounina, E.; Nunes, R.; Costa, A.; Sarmento, B.; Hasnain, S. Z.; Ross, B. P.; Popat, A. Rationally designed dendritic silica nanoparticles for oral delivery of exenatide. Pharmaceutics 2019, 11 (8). https:// doi.org/10.3390/pharmaceutics 11080418

7. G. Øye, J. Sjöblom, M. Stöcker, Synthesis, characterization and potential applications of new materials in the mesoporous range. Adv. Colloid Interf. Sci. 89-90, 439-466 (2001). https://doi.org/ 10.1016/S0001-8686(00)00066-X

8. M. Prokopowicz, A. Szewczyk, A. Skwira, R. Sądej, G. Walker, Biphasic composite of calcium phosphate-based mesoporous silica as a novel bone drug delivery system. Drug Deliv Transl Res 
10(2), 455-470 (2020). https://doi.org/10.1007/s13346-01900686-3

9. X. Ji, Z. Su, P. Wang, G. Ma, S. Zhang, "Ready-to-use" hollow nanofiber membrane-based glucose testing strips. Analyst 139(24), 6467-6473 (2014). https://doi.org/10.1039/c4an01354a

10. R. Ryoo, J.M. Kim, Structural order in MCM-41 controlled by shifting silicate polymerization equilibrium. J. Chem. Soc. Chem. Commun. (7), 711-712 (1995). https://doi.org/10.1039/ C39950000711

11. D. Khushalani, A. Kuperman, G.A. Ozin, K. Tanaka, N. Coombs, M.M. Olken, J. Garcés, Metamorphic materials: restructuring siliceous mesoporous materials. Adv. Mater. 7(10), 842-846 (1995). https://doi.org/10.1002/adma.19950071005

12. K.J. Edler, J.W. White, Further improvements in the long-range order of MCM-41 materials. Chem. Mater. 9(5), 1226-1233 (1997). https://doi.org/10.1021/cm9606033

13. H.P. Lin, S. Cheng, C.Y. Mou, Effect of delayed neutralization on the synthesis of mesoporous MCM-41 molecular sieves. Microporous Mater 10(1-3), 111-121 (1997). https://doi.org/10. 1016/S0927-6513(96)00125-3

14. F.H.P. Silva, H.O. Pastore, The syntheses of mesoporous molecular sieves in fluoride medium. Chem. Commun. 7, 833 (2004). https://doi.org/10.1039/cc9960000833

15. M. Kruk, M. Jaroniec, A. Sayari, Influence of hydrothermal restructuring conditions on structural properties of mesoporous molecular sieves. Microporous Mesoporous Mater. 27(2-3), 217-229 (1999). https://doi.org/10.1016/S1387-1811(98)00256$\mathrm{X}$

16. L. Chen, T. Horiuchi, T. Mori, K. Maeda, Postsynthesis hydrothermal restructuring of M41S mesoporous molecular sieves in water. J. Phys. Chem. B 103(8), 1216-1222 (2002). https://doi. org/10.1021/jp983100o

17. H.P. Lin, S. Cheng, C.Y. Mou, Mesoporous molecular sieves MCM-41 with a hollow tubular morphology. Chem. Mater. 10(2), 581-589 (1998). https://doi.org/10.1021/cm9705754

18. D. Zhao, Q. Huo, J. Feng, B.F. Chmelka, G.D. Stucky, Nonionic triblock and star Diblock copolymer and oligomeric Sufactant syntheses of highly ordered, hydrothermally stable, mesoporous silica structures. J. Am. Chem. Soc. 120(24), 6024-6036 (1998). https://doi.org/10.1021/ja974025i

19. J.S. Beck, J.C. Vartuli, G.J. Kennedy, C.T. Kresge, W.J. Roth, S.E. Schramm, Molecular or supramolecular templating: defining the role of surfactant chemistry in the formation of microporous and mesoporous molecular sieves. Chem. Mater. 6(10), 18161821 (2005). https://doi.org/10.1021/cm00046a040

20. Z. Yi, L.F. Dumée, C.J. Garvey, C. Feng, F. She, J.E. Rookes, S. Mudie, D.M. Cahill, L. Kong, A new insight into growth mechanism and kinetics of mesoporous silica nanoparticles by in situ small angle X-ray scattering. Langmuir 31(30), 8478-8487 (2015). https://doi.org/10.1021/acs.langmuir.5b01637

21. J.S. Beck, J.C. Vartuli, W.J. Roth, M.E. Leonowicz, C.T. Kresge, K.D. Schmitt, C.T.W. Chu, D.H. Olson, E.W. Sheppard, S.B. McCullen, J.B. Higgins, J.L. Schlenker, A new family of mesoporous molecular sieves prepared with liquid crystal templates. J. Am. Chem. Soc. 114(27), 10834-10843 (1992). https://doi.org/ $10.1021 / \mathrm{ja} 00053 \mathrm{a} 020$

22. K.J. Edler, Current understanding of formation mechanisms in surfactant-templated materials. Aust. J. Chem. 58(9), 627 (2005). https://doi.org/10.1071/ch05141

23. R. Narayan, U.Y. Nayak, A.M. Raichur, S. Garg, Mesoporous silica nanoparticles: a comprehensive review on synthesis and recent advances. Pharmaceutics 10(3), 118 (2018). https://doi. org/10.3390/pharmaceutics10030118

24. M. Manzano, M. Vallet-Regí, Mesoporous silica nanoparticles for drug delivery. Adv. Funct. Mater. 30(2), 1902634 (2020). https:// doi.org/10.1002/adfm.201902634
25. W. Wang, P. Wang, X. Tang, A.A. Elzatahry, S. Wang, D. AlDahyan, M. Zhao, C. Yao, C.-T. Hung, X. Zhu, T. Zhao, X. Li, F. Zhang, D. Zhao, Facile synthesis of uniform virus-like mesoporous silica nanoparticles for enhanced cellular internalization. ACS Cent Sci 3(8), 839-846 (2017). https://doi.org/10.1021/ acscentsci.7b00257

26. A. El-Toni, M. Ibrahim, J. Labis, A. Khan, M. Alhoshan, Optimization of synthesis parameters for mesoporous shell formation on magnetic nanocores and their application as nanocarriers for docetaxel cancer drug. Int. J. Mol. Sci. 14(6), 11496-11509 (2013). https://doi.org/10.3390/ijms140611496

27. M. Bouchoucha, M.F. Côté, R. C-Gaudreault, M.A. Fortin, F. Kleitz, Size-controlled functionalized mesoporous silica nanoparticles for tunable drug release and enhanced anti-tumoral activity. Chem. Mater. 28(12), 4243-4258 (2016). https://doi.org/10.1021/ acs.chemmater.6b00877

28. Z.A. Qiao, L. Zhang, M. Guo, Y. Liu, Q. Huo, Synthesis of mesoporous silica nanoparticles via controlled hydrolysis and condensation of silicon alkoxide. Chem. Mater. 21(16), 3823-3829 (2009). https://doi.org/10.1021/cm901335k

29. P.L. Abbaraju, A. Meka, S. Kumar Jambhrunkar, J. Zhang, C. Xu, A. Popat, C. Yu, Floating tablets from mesoporous silica nanoparticles. J. Mater. Chem. B 2(47), 8298-8302 (2014). https://doi.org/ 10.1039/C4TB01337A

30. A. Ganguly, T. Ahmad, A.K. Ganguli, Silica mesostructures: control of pore size and surface area using a surfactant-templated hydrothermal process. Langmuir 26(18), 14901-14908 (2010). https://doi.org/10.1021/la102510c

31. Y.D. Chiang, H.Y. Lian, S.Y. Leo, S.G. Wang, Y. Yamauchi, K.C.W. Wu, Controlling particle size and structural properties of mesoporous silica nanoparticles using the Taguchi method. J. Phys. Chem. C 115(27), 13158-13165 (2011). https://doi.org/ 10.1021/jp201017e

32. M. Gu, X. Wang, T.B. Toh, E.K.-H. Chow, Applications of stimuli-responsive nanoscale drug delivery systems in translational research. Drug Discov. Today 23(5), 1043-1052 (2018). https:// doi.org/10.1016/j.drudis.2017.11.009

33. J. Li, Y.J. Ma, Y. Wang, B.Z. Chen, X.D. Guo, C.Y. Zhang, Dual redox/PH-responsive hybrid polymer-lipid composites: synthesis, preparation, characterization and application in drug delivery with enhanced therapeutic efficacy. Chem. Eng. J. 341, 450-461 (2018). https://doi.org/10.1016/j.cej.2018.02.055

34. X. Hu, J. Tian, T. Liu, G. Zhang, S. Liu, Photo-triggered release of caged camptothecin prodrugs from dually responsive shell crosslinked micelles. Macromolecules 46(15), 6243-6256 (2013). https://doi.org/10.1021/ma400691j

35. K. Radhakrishnan, J. Tripathy, D.P. Gnanadhas, D. Chakravortty, A.M. Raichur, Dual enzyme responsive and targeted nanocapsules for intracellular delivery of anticancer agents. RSC Adv. 4(86), 45961-45968 (2014). https://doi.org/10.1039/C4RA07815B

36. D. Rosenblum, N. Joshi, W. Tao, J.M. Karp, D. Peer, Progress and challenges towards targeted delivery of cancer therapeutics. Nat. Commun. 9(1), 1410 (2018). https://doi.org/10.1038/s41467-01803705-y

37. Y. Song, Y. Li, Q. Xu, Z. Liu, Mesoporous silica nanoparticles for stimuli-responsive controlled drug delivery: advances, challenges, and outlook. Int. J. Nanomedicine 12, 87-110 (2017). https://doi. org/10.2147/IJN.S117495

38. J. Chen, M. Liu, C. Chen, H. Gong, C. Gao, Synthesis and characterization of silica nanoparticles with well-defined thermoresponsive PNIPAM via a combination of RAFT and click chemistry. ACS Appl. Mater. Interfaces 3(8), 3215-3223 (2011). https://doi.org/10.1021/am2007189

39. E.G. Fuller, H. Sun, R.D. Dhavalikar, M. Unni, G.M. Scheutz, B.S. Sumerlin, C. Rinaldi, Externally triggered heat and drug release from magnetically controlled nanocarriers. ACS Appl Polym 
Mater 1(2), 211-220 (2019). https://doi.org/10.1021/acsapm. $8 \mathrm{~b} 00100$

40. A. Baeza, E. Guisasola, E. Ruiz-Hernández, M. Vallet-Regí, Magnetically triggered multidrug release by hybrid mesoporous silica nanoparticles. Chem. Mater. 24(3), 517-524 (2012). https:// doi.org/10.1021/cm203000u

41. E. Guisasola, A. Baeza, M. Talelli, D. Arcos, M. Moros, J.M. de la Fuente, M. Vallet-Regí, Magnetic-responsive release controlled by hot spot effect. Langmuir 31(46), 12777-12782 (2015). https://doi.org/10.1021/acs.langmuir.5b03470

42. H.G. Reichenbach, V. Schwertmann, U. Und, R.M. Cornell, Iron oxides in the laboratory - preparation and characterization. $\mathrm{VCH}$ Verlagsgesellschaft, Weinheim 1991; 137 Seiten, 40 Abbildungen, 4 Tabellen, Hardcover, 118,- DM. ISBN 3-52726991-6. Z. Pflanzenernähr. Bodenkd. 155(3), 254 (1992). https://doi.org/10.1002/jpln.19921550321

43. Q. Guo, Y. Liu, K. Xu, K. Ren, W. Sun, Mouse lymphatic endothelial cell targeted probes: anti-LYVE-1 antibody-based magnetic nanoparticles. Int. J. Nanomedicine 8, 2273-2284 (2013). https://doi.org/10.2147/IJN.S45817

44. T. Koyama, M. Shimura, Y. Minemoto, S. Nohara, S. Shibata, Y. Iida, S. Iwashita, M. Hasegawa, T. Kurabayashi, H. Hamada, K. Kono, E. Honda, I. Aoki, Y. Ishizaka, Evaluation of selective tumor detection by clinical magnetic resonance imaging using antibody-conjugated superparamagnetic iron oxide. J. Control. Release 159(3), 413-418 (2012). https://doi.org/10.1016/j. jconrel.2012.01.023

45. R. Meier, T.D. Henning, S. Boddington, S. Tavri, S. Arora, G. Piontek, M. Rudelius, C. Corot, H.E. Daldrup-Link, Breast cancers: MR imaging of folate-receptor expression with the folatespecific nanoparticle P1133. Radiology 255(2), 527-535 (2010). https://doi.org/10.1148/radiol.10090050

46. J. Li, L. Zheng, H. Cai, W. Sun, M. Shen, G. Zhang, X. Shi, Polyethyleneimine-mediated synthesis of folic acid-targeted iron oxide nanoparticles for in vivo tumor MR imaging. Biomaterials 34(33), 8382-8392 (2013). https://doi.org/10.1016/j.biomaterials. 2013.07.070

47. A.S. Fortuin, H. Meijer, L.C. Thompson, J. Alfred Witjes, J.O. Barentsz, Ferumoxtran-10 ultrasmall superparamagnetic iron oxide-enhanced diffusion-weighted imaging magnetic resonance imaging for detection of metastases in Normal-sized lymph nodes in patients with bladder and prostate cancer: do we enter the era after extended. Eur. Urol. 64(6), 961-963 (2013). https://doi.org/ 10.1016/j.eururo.2013.08.017

48. G. von Maltzahn, Y. Ren, J.-H. Park, D.-H. Min, V.R. Kotamraju, J. Jayakumar, V. Fogal, M.J. Sailor, E. Ruoslahti, S.N. Bhatia, In vivo tumor cell targeting with "click" nanoparticles. Bioconjug. Chem. 19(8), 1570-1578 (2008). https://doi.org/10. 1021/bc800077y

49. Y. Jiang, S. Liu, Y. Zhang, H. Li, H. He, J. Dai, T. Jiang, W. Ji, D. Geng, A.A. Elzatahry, A. Alghamdi, D. Fu, Y. Deng, D. Zhao, Magnetic mesoporous nanospheres anchored with LyP-1 as an efficient pancreatic cancer probe. Biomaterials 115, 9-18 (2017). https://doi.org/10.1016/j.biomaterials.2016.11.006

50. X. Yao, X. Niu, K. Ma, P. Huang, J. Grothe, S. Kaskel, Y. Zhu, Graphene quantum dots-capped magnetic mesoporous silica nanoparticles as a multifunctional platform for controlled drug delivery, magnetic hyperthermia, and photothermal therapy. Small 13(2), 1602225 (2017). https://doi.org/10.1002/smll. 201602225

51. Y. Zhang, Q. Yue, M.M. Zagho, J. Zhang, A.A. Elzatahry, Y. Jiang, Y. Deng, Core-shell magnetic mesoporous silica microspheres with large mesopores for enzyme immobilization in biocatalysis. ACS Appl. Mater. Interfaces 11(10), 10356-10363 (2019). https://doi.org/10.1021/acsami.8b18721
52. H.C. Janßen, N. Angrisani, S. Kalies, F. Hansmann, M. Kietzmann, D.P. Warwas, P. Behrens, J. Reifenrath, Biodistribution, biocompatibility and targeted accumulation of magnetic nanoporous silica nanoparticles as drug carrier in orthopedics. J Nanobiotechnology 18(1), 14 (2020). https://doi.org/10. 1186/s12951-020-0578-8

53. Yavuz, M. S.; Cheng, Y.; Chen, J.; Cobley, C. M.; Zhang, Q.; Rycenga, M.; Xie, J.; Kim, C.; Song, K. H.; Schwartz, A. G.; Wang, L. V; Xia, Y. Gold nanocages covered by smart polymers for controlled release with near-infrared light. Nat. Mater. 2009, 8 (12), 935-939. https://doi.org/10.1038/nmat2564

54. N. Li, Z. Yu, W. Pan, Y. Han, T. Zhang, B. Tang, A near-infrared light-triggered Nanocarrier with reversible DNA valves for intracellular controlled release. Adv. Funct. Mater. 23(18), 2255-2262 (2013). https://doi.org/10.1002/adfm.201202564

55. Tang, H.; Shen, S.; Guo, J.; Chang, B.; Jiang, X.; Yang, W. Gold nanorods@mSiO2 with a smart polymer shell responsive to heat/ near-infrared light for chemo-photothermal therapy; 2012; Vol. 22. https://doi.org/10.1039/C2JM32599C

56. G. Yang, X. Sun, J. Liu, L. Feng, Z. Liu, Light-responsive, singletoxygen-triggered on-demand drug release from photosensitizerdoped mesoporous silica nanorods for cancer combination therapy. Adv. Funct. Mater. 26(26), 4722-4732 (2016). https://doi.org/ 10.1002/adfm.201600722

57. P. Huang, J. Lin, S. Wang, Z. Zhou, Z. Li, Z. Wang, C. Zhang, X. Yue, G. Niu, M. Yang, D. Cui, X. Chen, Photosensitizerconjugated silica-coated gold nanoclusters for fluorescence imaging-guided photodynamic therapy. Biomaterials 34(19), 4643-4654 (2013). https://doi.org/10.1016/j.biomaterials.2013. 02.063

58. Y. Liu, Y. Liu, W. Bu, C. Cheng, C. Zuo, Q. Xiao, Y. Sun, D. Ni, C. Zhang, J. Liu, J. Shi, Hypoxia induced by upconversion-based photodynamic therapy: towards highly effective synergistic bioreductive therapy in tumors. Angew. Chem. Int. Ed. Eng. 54(28), 8105-8109 (2015). https://doi.org/10.1002/anie. 201500478

59. J. Liu, H. Liang, M. Li, Z. Luo, J. Zhang, X. Guo, K. Cai, Tumor acidity activating multifunctional Nanoplatform for NIR-mediated multiple enhanced photodynamic and photothermal tumor therapy. Biomaterials 157, 107-124 (2018). https://doi.org/10.1016/j. biomaterials.2017.12.003

60. J. Liu, Y. Liu, W. Bu, J. Bu, Y. Sun, J. Du, J. Shi, Ultrasensitive nanosensors based on upconversion nanoparticles for selective hypoxia imaging in vivo upon near-infrared excitation. J. Am. Chem. Soc. 136(27), 9701-9709 (2014). https://doi.org/10.1021/ ja5042989

61. W.-P. Li, P.-Y. Liao, C.-H. Su, C.-S. Yeh, Formation of oligonucleotide-gated silica shell-coated Fe3O4-au core-shell nanotrisoctahedra for magnetically targeted and near-infrared light-responsive theranostic platform. J. Am. Chem. Soc. 136(28), 10062-10075 (2014). https://doi.org/10.1021/ ja504118q

62. Q. Sun, Q. You, J. Wang, L. Liu, Y. Wang, Y. Song, Y. Cheng, S. Wang, F. Tan, N. Li, Theranostic nanoplatform: triple-modal imaging-guided synergistic cancer therapy based on liposomeconjugated mesoporous silica nanoparticles. ACS Appl. Mater. Interfaces 10(2), 1963-1975 (2018). https://doi.org/10.1021/ acsami. $7 b 13651$

63. Y. Zhang, Z. Hou, Y. Ge, K. Deng, B. Liu, X. Li, Q. Li, Z. Cheng, P. Ma, C. Li, J. Lin, DNA-hybrid-gated photothermal mesoporous silica nanoparticles for NIR-responsive and aptamer-targeted drug delivery. ACS Appl. Mater. Interfaces 7(37), 20696-20706 (2015). https://doi.org/10.1021/acsami.5b05522

64. L. Yang, J. Wang, S. Yang, Q. Lu, P. Li, N. Li, Rod-shape MSN@MoS(2) Nanoplatform for FL/MSOT/CT imaging- 
guided photothermal and photodynamic therapy. Theranostics 9(14), 3992-4005 (2019). https://doi.org/10.7150/thno.32715

65. J.L. Vivero-Escoto, I.I. Slowing, C.-W. Wu, V.S.-Y. Lin, Photoinduced intracellular controlled release drug delivery in human cells by gold-capped mesoporous silica nanosphere. J. Am. Chem. Soc. 131(10), 3462-3463 (2009). https://doi.org/10.1021/ ja900025f

66. Y. Inoue, P. Kuad, Y. Okumura, Y. Takashima, H. Yamaguchi, A. Harada, Thermal and photochemical switching of conformation of poly(ethylene glycol)-substituted cyclodextrin with an azobenzene group at the chain end. J. Am. Chem. Soc. 129(20), 6396-6397 (2007). https://doi.org/10.1021/ja071717q

67. J. Liu, W. Bu, L. Pan, J. Shi, NIR-triggered anticancer drug delivery by upconverting nanoparticles with integrated azobenzenemodified mesoporous silica. Angew. Chem. Int. Ed. Eng. 52(16), 4375-4379 (2013). https://doi.org/10.1002/anie. 201300183

68. G. Wang, J. Dong, T. Yuan, J. Zhang, L. Wang, H. Wang, Visible light and $\mathrm{PH}$ responsive polymer-coated mesoporous silica nanohybrids for controlled release. Macromol. Biosci. 16(7), 990-994 (2016). https://doi.org/10.1002/mabi.201600008

69. I. Lavon, J. Kost, Mass transport enhancement by ultrasound in non-degradable polymeric controlled release systems. J. Control. Release 54(1), 1-7 (1998)

70. J.L. Paris, M.V. Cabañas, M. Manzano, M. Vallet-Regí, Polymergrafted mesoporous silica nanoparticles as ultrasound-responsive drug carriers. ACS Nano 9(11), 11023-11033 (2015). https://doi. org/10.1021/acsnano.5b04378

71. I.F. Tannock, D. Rotin, Acid PH in tumors and its potential for therapeutic exploitation. Cancer Res. 49(16), 4373-4384 (1989)

72. Q. Gao, Y. Xu, D. Wu, Y. Sun, X. Li, PH-responsive drug release from polymer-coated mesoporous silica spheres. J. Phys. Chem. C 113(29), 12753-12758 (2009). https://doi.org/10.1021/jp9043978

73. C.-H. Lee, S.-H. Cheng, I.-P. Huang, J.S. Souris, C.-S. Yang, C.Y. Mou, L.-W. Lo, Intracellular PH-responsive mesoporous silica nanoparticles for the controlled release of anticancer chemotherapeutics. Angew. Chem. 122(44), 8390-8395 (2010). https://doi. org/10.1002/ange.201002639

74. M. Martínez-Carmona, D. Lozano, M. Colilla, M. Vallet-Regí, Lectin-conjugated $\mathrm{PH}-$ responsive mesoporous silica nanoparticles for targeted bone cancer treatment. Acta Biomater. 65, 393-404 (2018). https://doi.org/10.1016/j.actbio.2017.11.007

75. R. Liu, Y. Zhang, X. Zhao, A. Agarwal, L.J. Mueller, P. Feng, PHresponsive nanogated ensemble based on gold-capped mesoporous silica through an acid-labile acetal linker. J. Am. Chem. Soc. 132(5), 1500-1501 (2010). https://doi.org/10.1021/ ja907838s

76. F. Muhammad, M. Guo, W. Qi, F. Sun, A. Wang, Y. Guo, G. Zhu, $\mathrm{PH}$-triggered controlled drug release from mesoporous silica nanoparticles via intracelluar dissolution of $\mathrm{ZnO}$ nanolids. J. Am. Chem. Soc. 133(23), 8778-8781 (2011). https://doi.org/10. 1021/ja200328s

77. G.K. Nasrallah, Y. Zhang, M.M. Zagho, H.M. Ismail, A.A. AlKhalaf, R.M. Prieto, K.E. Albinali, A.A. Elzatahry, Y. Deng, A systematic investigation of the bio-toxicity of Core-Shell magnetic mesoporous silica microspheres using zebrafish model. Microporous Mesoporous Mater. 265, 195-201 (2018). https:// doi.org/10.1016/j.micromeso.2018.02.008

78. A. Bernardos, L. Mondragon, E. Aznar, M.D. Marcos, R. Martinez-Mañez, F. Sancenon, J. Soto, J.M. Barat, E. PerezPaya, C. Guillem, P. Amoros, Enzyme-responsive intracellular controlled release using nanometric silica mesoporous supports capped with "saccharides". ACS Nano 4(11), 6353-6368 (2010). https://doi.org/10.1021/nn101499d

79. A. Bernardos, E. Aznar, M.D. Marcos, R. Martínez-Máñez, F. Sancenón, J. Soto, J.M. Barat, P. Amorós, Enzyme-responsive controlled release using mesoporous silica supports capped with lactose. Angew. Chem. Int. Ed. Eng. 48(32), 5884-5887 (2009). https://doi.org/10.1002/anie.200900880

80. Z. Zou, X. He, D. He, K. Wang, Z. Qing, X. Yang, L. Wen, J. Xiong, L. Li, L. Cai, Programmed packaging of mesoporous silica nanocarriers for matrix metalloprotease 2-triggered tumor targeting and release. Biomaterials 58, 35-45 (2015). https://doi. org/10.1016/j.biomaterials.2015.04.034

81. J. Gallo, N. Kamaly, I. Lavdas, E. Stevens, Q.-D. Nguyen, M. Wylezinska-Arridge, E.O. Aboagye, N.J. Long, CXCR4targeted and MMP-responsive iron oxide nanoparticles for enhanced magnetic resonance imaging. Angew. Chem. Int. Ed. Eng. 53(36), 9550-9554 (2014). https://doi.org/10.1002/anie. 201405442

82. S.H. van Rijt, D.A. Bolukbas, C. Argyo, S. Datz, M. Lindner, O. Eickelberg, M. Konigshoff, T. Bein, S. Meiners, Proteasemediated release of chemotherapeutics from mesoporous silica nanoparticles to ex vivo human and mouse lung tumors. ACS Nano 9(3), 2377-2389 (2015). https://doi.org/10.1021/ nn5070343

83. Y.-J. Cheng, G.-F. Luo, J.-Y. Zhu, X.-D. Xu, X. Zeng, D.-B. Cheng, Y.-M. Li, Y. Wu, X.-Z. Zhang, R.-X. Zhuo, F. He, Enzyme-induced and tumor-targeted drug delivery system based on multifunctional mesoporous silica nanoparticles. ACS Appl. Mater. Interfaces 7(17), 9078-9087 (2015). https://doi.org/10. 1021/acsami.5b00752

84. G. Saito, J.A. Swanson, K.-D. Lee, Drug delivery strategy utilizing conjugation via reversible disulfide linkages: role and site of cellular reducing activities. Adv. Drug Deliv. Rev. 55(2), 199-215 (2003)

85. C.-Y. Lai, B.G. Trewyn, D.M. Jeftinija, K. Jeftinija, S. Xu, S. Jeftinija, V.S.-Y. Lin, A mesoporous silica nanosphere-based carrier system with chemically removable $\mathrm{CdS}$ nanoparticle caps for stimuli-responsive controlled release of neurotransmitters and drug molecules. J. Am. Chem. Soc. 125(15), 4451-4459 (2003). https://doi.org/10.1021/ja0286501.

86. S. Wu, X. Huang, X. Du, PH- and redox-triggered synergistic controlled release of a $\mathrm{ZnO}$-gated hollow mesoporous silica drug delivery system. J. Mater. Chem. B 3(7), 1426-1432 (2015). https://doi.org/10.1039/C4TB01794C

87. S. Giri, B.G. Trewyn, M.P. Stellmaker, V.S.-Y. Lin, Stimuliresponsive controlled-release delivery system based on mesoporous silica nanorods capped with magnetic nanoparticles. Angew. Chem. Int. Ed. Eng. 44(32), 5038-5044 (2005). https://doi.org/10. 1002/anie.200501819

88. P. Nadrah, U. Maver, A. Jemec, T. Tišler, M. Bele, G. Dražić, M. Benčina, A. Pintar, O. Planinšek, M. Gaberšček, Hindered disulfide bonds to regulate release rate of model drug from mesoporous silica. ACS Appl. Mater. Interfaces 5(9), 3908-3915 (2013). https://doi.org/10.1021/am400604d

89. Y. Wang, N. Han, Q. Zhao, L. Bai, J. Li, T. Jiang, S. Wang, Redox-responsive mesoporous silica as carriers for controlled drug delivery: A comparative study based on silica and PEG gatekeepers. Eur. J. Pharm. Sci. 72, 12-20 (2015). https://doi.org/10. 1016/j.ejps.2015.02.008

90. Q. Zhao, C. Wang, Y. Liu, J. Wang, Y. Gao, X. Zhang, T. Jiang, S. Wang, PEGylated mesoporous silica as a redox-responsive drug delivery system for loading thiol-containing drugs. Int. J. Pharm. 477(1-2), 613-622 (2014). https://doi.org/10.1016/j. ijpharm.2014.10.056

91. Q. Zhang, F. Liu, K.T. Nguyen, X. Ma, X. Wang, B. Xing, Y. Zhao, Multifunctional mesoporous silica nanoparticles for cancertargeted and controlled drug delivery. Adv. Funct. Mater. 22(24), 5144-5156 (2012). https://doi.org/10.1002/adfm.201201316

92. X. Ma, C. Teh, Q. Zhang, P. Borah, C. Choong, V. Korzh, Y. Zhao, Redox-responsive mesoporous silica nanoparticles: a 
physiologically sensitive codelivery vehicle for SiRNA and doxorubicin. Antioxid. Redox Signal. 21(5), 707-722 (2014). https:// doi.org/10.1089/ars.2012.5076

93. T. Traitel, Y. Cohen, J. Kost, Characterization of glucose-sensitive insulin release systems in simulated in vivo conditions. Biomaterials 21(16), 1679-1687 (2000)

94. Z. Zou, D. He, L. Cai, X. He, K. Wang, X. Yang, L. Li, S. Li, X. $\mathrm{Su}$, Alizarin complexone functionalized mesoporous silica nanoparticles: a smart system integrating glucose-responsive doubledrugs release and real-time monitoring capabilities. ACS Appl. Mater. Interfaces 8(13), 8358-8366 (2016). https://doi.org/10. 1021/acsami.5b12576

95. N.G. Lamson, A. Berger, K.C. Fein, K.A. Whitehead, Anionic nanoparticles enable the oral delivery of proteins by enhancing intestinal permeability. Nat Biomed Eng 4(1), 84-96 (2020). https://doi.org/10.1038/s41551-019-0465-5

96. F.M. Gribble, G. Loussouarn, S.J. Tucker, C. Zhao, C.G. Nichols, F.M. Ashcroft, A novel method for measurement of submembrane ATP concentration. J. Biol. Chem. 275(39), 30046-30049 (2000). https://doi.org/10.1074/jbc.M001010200

97. R. Mo, T. Jiang, R. DiSanto, W. Tai, Z. Gu, ATP-Nat.Triggered Anticancer Drug Delivery. Commun 5, 3364 (2014)

98. M.M. Gottesman, T. Fojo, S.E. Bates, Multidrug resistance in cancer: role of ATP-dependent transporters. Nat. Rev. Cancer 2(1), 48-58 (2002). https://doi.org/10.1038/nrc706

99. F.-F. Zheng, P.-H. Zhang, Y. Xi, J.-J. Chen, L.-L. Li, J.-J. Zhu, Aptamer/graphene quantum dots nanocomposite capped fluorescent mesoporous silica nanoparticles for intracellular drug delivery and real-time monitoring of drug release. Anal. Chem. 87(23), 11739-11745 (2015). https://doi.org/10.1021/acs.analchem. 5 b03131

100. Y. Matsumura, H. Maeda, A new concept for macromolecular therapeutics in cancer chemotherapy: mechanism of tumoritropic accumulation of proteins and the antitumor agent Smancs. Cancer Res. 46(12 Pt 1), 6387-6392 (1986)

101. Y.-N. Zhang, W. Poon, A.J. Tavares, I.D. McGilvray, W.C.W. Chan, Nanoparticle-liver interactions: cellular uptake and hepatobiliary elimination. J. Control. Release 240, 332-348 (2016). https://doi.org/10.1016/j.jconrel.2016.01.020

102. J.E. Lee, N. Lee, T. Kim, J. Kim, T. Hyeon, Multifunctional mesoporous silica nanocomposite nanoparticles for theranostic applications. Acc. Chem. Res. 44(10), 893-902 (2011). https:// doi.org/10.1021/ar2000259

103. R.A. Petros, J.M. DeSimone, Strategies in the design of nanoparticles for therapeutic applications. Nat. Rev. Drug Discov. 9(8), 615-627 (2010). https://doi.org/10.1038/nrd2591

104. H. Maeda, J. Wu, T. Sawa, Y. Matsumura, K. Hori, Tumor vascular permeability and the EPR effect in macromolecular therapeutics: a review. J. Control. Release 65(1-2), 271-284 (2000)

105. Q. He, Z. Zhang, F. Gao, Y. Li, J. Shi, In vivo biodistribution and urinary excretion of mesoporous silica nanoparticles: effects of particle size and PEGylation. Small 7(2), 271-280 (2011). https://doi.org/10.1002/smll.201001459

106. F. Lu, S.-H. Wu, Y. Hung, C.-Y. Mou, Size effect on cell uptake in well-suspended. Uniform Mesoporous Silica Nanoparticles Small 5(12), 1408-1413 (2009). https://doi.org/10.1002/smll. 200900005

107. B.D. Chithrani, A.A. Ghazani, W.C.W. Chan, Determining the size and shape dependence of gold nanoparticle uptake into mammalian cells. Nano Lett. 6(4), 662-668 (2006)

108. H.J. Gao, W.D. Shi, L.B. Freund, Mechanics of receptor-mediated endocytosis. Proc. Natl. Acad. Sci. 102, 9469-9474 (2005). https://doi.org/10.1073/pnas.0503879102

109. Biocompatible mesoporous silica nanoparticles with different morphologies for animal cell membrane, penetration. Chem. Eng. J. 2008, 137 (1), 23-29
110. X. Huang, X. Teng, D. Chen, F. Tang, J. He, The effect of the shape of mesoporous silica nanoparticles on cellular uptake and cell function. Biomaterials 31(3), 438-448 (2010). https://doi.org/ 10.1016/j.biomaterials.2009.09.060

111. H. Meng, S. Yang, Z. Li, T. Xia, J. Chen, Z. Ji, H. Zhang, X. Wang, S. Lin, C. Huang, Z.H. Zhou, J.I. Zink, A.E. Nel, Aspect ratio determines the quantity of mesoporous silica nanoparticle uptake by a small GTPase-dependent macropinocytosis mechanism. ACS Nano 5(6), 4434-4447 (2011). https://doi.org/10. $1021 / \mathrm{nn} 103344 \mathrm{k}$

112. D. Shao, M.-M. Lu, Y.-W. Zhao, F. Zhang, Y.-F. Tan, X. Zheng, Y. Pan, X.-A. Xiao, Z. Wang, W.-F. Dong, J. Li, L. Chen, The shape effect of magnetic mesoporous silica nanoparticles on endocytosis. Biocompatibility and Biodistribution Acta Biomater 49, 531-540 (2017). https://doi.org/10.1016/j.actbio.2016.11.007

113. Nel, A. E.; Madler, L.; Velegol, D.; Xia, T.; Hoek, E. M. V; Somasundaran, P.; Klaessig, F.; Castranova, V.; Thompson, M. Understanding biophysicochemical interactions at the nano-bio interface. Nat. Mater. 2009, 8 (7), 543-557. https://doi.org/10. 1038/nmat2442

114. I.I. Slowing, C.-W. Wu, J.L. Vivero-Escoto, V.S.-Y. Lin, Mesoporous silica nanoparticles for reducing hemolytic activity towards mammalian red blood cells. Small 5(1), 57-62 (2009). https://doi.org/10.1002/smll.200800926

115. Z. Teng, S. Wang, X. Su, G. Chen, Y. Liu, Z. Luo, W. Luo, Y. Tang, H. Ju, D. Zhao, G. Lu, Facile synthesis of yolk-Shell structured inorganic-organic hybrid spheres with ordered radial mesochannels. Adv. Mater. 26(22), 3741-3747 (2014). https:// doi.org/10.1002/adma.201400136

116. P.C. Ke, S. Lin, W.J. Parak, T.P. Davis, F. Caruso, A decade of the protein corona. ACS Nano 11(12), 11773-11776 (2017). https:// doi.org/10.1021/acsnano.7b08008

117. V. Cauda, C. Argyo, T. Bein, Impact of different pegylation patterns on the long-term bio-stability of colloidal. Mesoporous Silica Nanoparticles 20(39), 8693-8699 (2010). https://doi.org/10.1039/ c0jm01390k

118. Q. He, J. Zhang, J. Shi, Z. Zhu, L. Zhang, W. Bu, L. Guo, Y. Chen, The effect of PEGylation of mesoporous silica nanoparticles on nonspecific binding of serum proteins and cellular responses. Biomaterials 31(6), 1085-1092 (2010). https://doi.org/ 10.1016/j.biomaterials.2009.10.046

119. R. Rosenbrand, D. Barata, P. Sutthavas, R. Mohren, B. CilleroPastor, P. Habibovic, S. van Rijt, Lipid surface modifications increase mesoporous silica nanoparticle labeling properties in mesenchymal stem cells. Int. J. Nanomedicine 13, 7711-7725 (2018). https://doi.org/10.2147/IJN.S182428

120. T. Ishida, K. Masuda, T. Ichikawa, M. Ichihara, K. Irimura, H. Kiwada, Accelerated clearance of a second injection of PEGylated liposomes in mice. Int. J. Pharm. 255(1-2), 167-174 (2003)

121. J.E. Rosen, F.X. Gu, Surface functionalization of silica nanoparticles with cysteine: a low-fouling zwitterionic surface. Langmuir 27(17), 10507-10513 (2011). https://doi.org/10.1021/la201940r

122. C.E. Ashley, E.C. Carnes, G.K. Phillips, D. Padilla, P.N. Durfee, P.A. Brown, T.N. Hanna, J. Liu, B. Phillips, M.B. Carter, N.J. Carroll, X. Jiang, D.R. Dunphy, C.L. Willman, D.N. Petsev, D.G. Evans, A.N. Parikh, B. Chackerian, W. Wharton, D.S. Peabody, C.J. Brinker, The targeted delivery of multicomponent cargos to cancer cells by nanoporous particle-supported lipid bilayers. Nat. Mater. 10(5), 389-397 (2011). https://doi.org/10. 1038/nmat2992

123. Y.-Y. Yuan, C.-Q. Mao, X.-J. Du, J.-Z. Du, F. Wang, J. Wang, Surface charge switchable nanoparticles based on zwitterionic polymer for enhanced drug delivery to tumor. Adv. Mater. 24(40), 5476-5480 (2012). https://doi.org/10.1002/adma. 201202296 
124. Z. Chaudhary, G.M. Khan, M.M. Abeer, N. Pujara, B. Wan-Chi Tse, M.A. McGuckin, A. Popat, T. Kumeria, Efficient photoacoustic imaging using indocyanine green (ICG) loaded functionalized mesoporous silica nanoparticles. Biomater Sci 7(12), 50025015 (2019). https://doi.org/10.1039/C9BM00822E

125. Meka, A. K.; Jenkins, L. J.; Dàvalos-Salas, M.; Pujara, N.; Wong, K. Y.; Kumeria, T.; Mariadason, J. M.; Popat, A. Enhanced solubility, permeability and anticancer activity of vorinostat using tailored mesoporous silica nanoparticles. Pharmaceutics 2018, 10 (4). https://doi.org/10.3390/pharmaceutics10040283

126. Z. Chaudhary, S. Subramaniam, G.M. Khan, M.M. Abeer, Z. Qu, T. Janjua, T. Kumeria, J. Batra, A. Popat, Encapsulation and controlled release of resveratrol within functionalized mesoporous silica nanoparticles for prostate cancer therapy. Front Bioeng Biotechnol 7, 225 (2019). https://doi.org/10.3389/fbioe.2019. 00225

127. D. Peer, J.M. Karp, S. Hong, O.C. Farokhzad, R. Margalit, R. Langer, Nanocarriers as an emerging platform for cancer therapy. Nat. Nanotechnol. 2(12), 751-760 (2007). https://doi.org/10. 1038/nnano.2007.387

128. Y. Chen, H. Zhang, X. Cai, J. Ji, S. He, G. Zhai, Multifunctional mesoporous silica nanocarriers for stimuli-responsive target delivery of anticancer drugs. RSC Adv. 6(94), 92073-92091 (2016). https://doi.org/10.1039/C6RA18062K

129. P. Khosravian, M. Shafiee Ardestani, M. Khoobi, S.N. Ostad, F.A. Dorkoosh, H. Akbari Javar, M. Amanlou, Mesoporous silica nanoparticles functionalized with folic acid/methionine for active targeted delivery of docetaxel. Onco Targets Ther 9, 7315-7330 (2016). https://doi.org/10.2147/OTT.S113815

130. J. Lu, Z. Li, J.I. Zink, F. Tamanoi, In vivo tumor suppression efficacy of mesoporous silica nanoparticles-based drug-delivery system: enhanced efficacy by folate modification. Nanomedicine 8(2), 212-220 (2012). https://doi.org/10.1016/j.nano.2011.06.002

131. K. AbouAitah, A. Swiderska-Sroda, A.A. Farghali, J. Wojnarowicz, A. Stefanek, S. Gierlotka, A. Opalinska, A.K. Allayeh, T. Ciach, W. Lojkowski, Folic acid-conjugated mesoporous silica particles as nanocarriers of natural prodrugs for cancer targeting and antioxidant action. Oncotarget 9(41), 2646626490 (2018). https://doi.org/10.18632/oncotarget.25470

132. D. Brevet, M. Gary-Bobo, L. Raehm, S. Richeter, O. Hocine, K. Amro, B. Loock, P. Couleaud, C. Frochot, A. Morere, P. Maillard, M. Garcia, J.-O. Durand, Mannose-targeted mesoporous silica nanoparticles for photodynamic therapy. Chem. Commun. (Camb.) (12), 1475-1477 (2009) https://doi.org/10.1039/ b900427k

133. J. Peng, K. Wang, W. Tan, X. He, C. He, P. Wu, F. Liu, Identification of live liver cancer cells in a mixed cell system using galactose-conjugated fluorescent nanoparticles. Talanta 71(2), 833-840 (2007). https://doi.org/10.1016/j.talanta.2006.05.064

134. M. Gary-Bobo, O. Hocine, D. Brevet, M. Maynadier, L. Raehm, S. Richeter, V. Charasson, B. Loock, A. Morere, P. Maillard, M. Garcia, J.-O. Durand, Cancer therapy improvement with mesoporous silica nanoparticles combining targeting, drug delivery and PDT. Int. J. Pharm. 423(2), 509-515 (2012). https://doi.org/10. 1016/j.ijpharm.2011.11.045

135. C.-P. Tsai, C.-Y. Chen, Y. Hung, F.-H. Chang, C.-Y. Mou, Monoclonal antibody-functionalized mesoporous silica nanoparticles (MSN) for selective targeting breast cancer cells. J. Mater. Chem. 19(32), 5737-5743 (2009). https://doi.org/10.1039/ B905158A

136. G. Gastl, G. Spizzo, P. Obrist, M. Dünser, G. Mikuz, Ep-CAM overexpression in breast cancer as a predictor of survival. Lancet 356(9246), 1981-1982 (2000). https://doi.org/10.1016/S01406736(00)03312-2

137. Y. Gao, S. Gu, Y. Zhang, X. Xie, T. Yu, Y. Lu, Y. Zhu, W. Chen, H. Zhang, H. Dong, P.J. Sinko, L. Jia, The architecture and function of monoclonal antibody-functionalized mesoporous silica nanoparticles loaded with mifepristone: repurposing abortifacient for cancer metastatic chemoprevention. Small 12(19), 2595 2608 (2016). https://doi.org/10.1002/smll.201600550

138. X. Xie, F. Li, H. Zhang, Y. Lu, S. Lian, H. Lin, Y. Gao, L. Jia, EpCAM aptamer-functionalized mesoporous silica nanoparticles for efficient colon cancer cell-targeted drug delivery. Eur. J. Pharm. Sci. 83, 28-35 (2016). https://doi.org/10.1016/j.ejps. 2015.12.014

139. D. Dreau, L.J. Moore, M.P. Alvarez-Berrios, M. Tarannum, P. Mukherjee, J.L. Vivero-Escoto, Mucin-1-antibody-conjugated mesoporous silica nanoparticles for selective breast cancer detection in a Mucin-1 transgenic murine mouse model. J. Biomed. Nanotechnol. 12(12), 2172-2184 (2016). https://doi.org/10. 1166/jbn.2016.2318

140. T. Mandal, M. Beck, N. Kirsten, M. Linden, C. Buske, Targeting murine leukemic stem cells by antibody functionalized mesoporous silica nanoparticles. Sci. Rep. 8(1), 989 (2018). https://doi. org/10.1038/s41598-017-18932-4

141. F. Wang, X. Liu, I. Willner, DNA switches: from principles to applications. Angew. Chem. Int. Ed. Eng. 54(4), 1098-1129 (2015). https://doi.org/10.1002/anie.201404652

142. Z. Zhang, D. Balogh, F. Wang, S.Y. Sung, R. Nechushtai, I. Willner, Biocatalytic release of an anticancer drug from nucleicacids-capped mesoporous $\mathrm{SiO} 2$ using DNA or molecular biomarkers as triggering stimuli. ACS Nano 7(10), 8455-8468 (2013). https://doi.org/10.1021/nn403772j

143. L. Pascual, C. Cerqueira-Coutinho, A. Garcia-Fernandez, B. de Luis, E.S. Bernardes, M.S. Albernaz, S. Missailidis, R. Martinez-Manez, R. Santos-Oliveira, M. Orzaez, F. Sancenon, MUC1 aptamer-capped mesoporous silica nanoparticles for controlled drug delivery and radio-imaging applications. Nanomedicine 13(8), 2495-2505 (2017). https://doi.org/10.1016/ j.nano.2017.08.006

144. Knudson, C. B.; Nofal, G. A.; Chow, G.; Peterson, R. S. CD44: the link between hyaluronan and the cytoskeleton; Kennedy, J. F., Phillips, G. O., Williams, P. A. B. T.-H., Eds.; Woodhead Publishing, 2002; pp 331-340. https://doi.org/10.1533/ 9781845693121.329

145. M. Yu, S. Jambhrunkar, P. Thorn, J. Chen, W. Gu, C. Yu, Hyaluronic acid modified mesoporous silica nanoparticles for targeted drug delivery to CD44-overexpressing cancer cells. Nanoscale 5(1), 178-183 (2013). https://doi.org/10.1039/ c2nr32145a

146. E.C. Lee, N. Davis-Poynter, C.T.H. Nguyen, A.A. Peters, G.R. Monteith, E. Strounina, A. Popat, B.P. Ross, GAG mimetic functionalised solid and mesoporous silica nanoparticles as viral entry inhibitors of herpes simplex type 1 and type 2 viruses. Nanoscale 8(36), 16192-16196 (2016). https://doi.org/10.1039/ C6NR03878F

147. Q. Lei, W.-X. Qiu, J.-J. Hu, P.-X. Cao, C.-H. Zhu, H. Cheng, X.Z. Zhang, Multifunctional mesoporous silica nanoparticles with thermal-responsive gatekeeper for NIR light-triggered chemo/ photothermal-therapy. Small 12(31), 4286-4298 (2016). https:// doi.org/10.1002/smll.201601137

148. N. Zhao, Z. Yang, B. Li, J. Meng, Z. Shi, P. Li, S. Fu, RGDconjugated mesoporous silica-encapsulated gold nanorods enhance the sensitization of triple-negative breast cancer to megavoltage radiation therapy. Int. J. Nanomedicine 11, 55955610 (2016). https://doi.org/10.2147/IJN.S104034

149. Y.-J. Cheng, A.-Q. Zhang, J.-J. Hu, F. He, X. Zeng, X.-Z. Zhang, Multifunctional peptide-amphiphile end-capped mesoporous silica nanoparticles for tumor targeting drug delivery. ACS Appl. Mater. Interfaces 9(3), 2093-2103 (2017). https://doi.org/10. 1021/acsami.6b12647 
150. C. Xu, Y. Cao, C. Lei, Z. Li, T. Kumeria, A.K. Meka, J. Xu, J. Liu, C. Yan, L. Luo, A. Khademhosseini, A. Popat, Y. He, Q. Ye, Polymer-mesoporous silica nanoparticle Core-Shell nanofibers as a dual-drug-delivery system for guided tissue regeneration. ACS Appl Nano Mater 3(2), 1457-1467 (2020). https://doi.org/ 10.1021/acsanm.9b02298

151. D. Hanahan, R.A. Weinberg, Hallmarks of cancer: the next generation. Cell 144(5), 646-674 (2011). https://doi.org/10.1016/j. cell.2011.02.013

152. D. Neri, R. Bicknell, Tumour vascular targeting. Nat. Rev. Cancer 5(6), 436-446 (2005). https://doi.org/10.1038/nrc1627

153. Y. Xiao, H. Hong, A. Javadi, J.W. Engle, W. Xu, Y. Yang, Y. Zhang, T.E. Barnhart, W. Cai, S. Gong, Multifunctional unimolecular micelles for cancer-targeted drug delivery and positron emission tomography imaging. Biomaterials 33(11), 30713082 (2012). https://doi.org/10.1016/j.biomaterials.2011.12.030

154. W.H. Woglom, A Critique of Tumor Resistance. J. Cancer Res. Ther. 7(4), 283-LP - 311 (1922). https://doi.org/10.1158/jcr. 1922.283

155. F.J. Burrows, P.E. Thorpe, Eradication of large solid tumors in mice with an immunotoxin directed against tumor vasculature. Proc. Natl. Acad. Sci. U. S. A. 90(19), 8996-9000 (1993)

156. S. Goel, F. Chen, H. Hong, H.F. Valdovinos, R. Hernandez, S. Shi, T.E. Barnhart, W. Cai, VEGF 121 -conjugated mesoporous silica nanoparticle: a tumor targeted drug delivery system. ACS Appl. Mater. Interfaces 6(23), 21677-21685 (2014). https://doi. org/10.1021/am506849p

157. G. Zheng, Y. Shen, R. Zhao, F. Chen, Y. Zhang, A. Xu, J. Shao, Dual-targeting multifuntional mesoporous silica nanocarrier for codelivery of SiRNA and ursolic acid to folate receptor overexpressing cancer cells. J. Agric. Food Chem. 65(32), 6904-6911 (2017). https://doi.org/10.1021/acs.jafc.7b03047

158. L. Pan, Q. He, J. Liu, Y. Chen, M. Ma, L. Zhang, J. Shi, Nucleartargeted drug delivery of TAT peptide-conjugated monodisperse mesoporous silica nanoparticles. J. Am. Chem. Soc. 134(13), 5722-5725 (2012). https://doi.org/10.1021/ja211035w

159. H. Mizutani, S. Tada-Oikawa, Y. Hiraku, M. Kojima, S. Kawanishi, Mechanism of apoptosis induced by doxorubicin through the generation of hydrogen peroxide. Life Sci. 76(13), 1439-1453 (2005). https://doi.org/10.1016/j.lfs.2004.05.040

160. J.G. Croissant, D. Zhang, S. Alsaiari, J. Lu, L. Deng, F. Tamanoi, A.M. AlMalik, J.I. Zink, N.M. Khashab, Protein-gold clusterscapped mesoporous silica nanoparticles for high drug loading, autonomous gemcitabine/doxorubicin co-delivery, and in-vivo tumor imaging. J. Control. Release 229, 183-191 (2016). https://doi. org/10.1016/j.jconrel.2016.03.030

161. Y. Yang, Y. Lin, D. Di, X. Zhang, D. Wang, Q. Zhao, S. Wang, Gold nanoparticle-gated mesoporous silica as redox-triggered drug delivery for chemo-photothermal synergistic therapy. J.
Colloid Interface Sci. 508, 323-331 (2017). https://doi.org/10. 1016/j.jcis.2017.08.050

162. C. Xu, J. Xie, N. Kohler, E.G. Walsh, Y.E. Chin, S. Sun, Monodisperse magnetite nanoparticles coupled with nuclear localization signal peptide for cell-nucleus targeting. Chem. Asian J. 3(3), 548-552 (2008). https://doi.org/10.1002/asia.200700301

163. F. Chen, D. Gerion, Fluorescent $\mathrm{CdSe} / \mathrm{ZnS}$ nanocrystal-peptide conjugates for long-term, nontoxic imaging and nuclear targeting in living cells. Nano Lett. 4(10), 1827-1832 (2004). https://doi. org/10.1021/nl049170q

164. X. Zhou, Q. Zhang, L. Chen, W. Nie, W. Wang, H. Wang, X. Mo, C. He, Versatile nanocarrier based on functionalized mesoporous silica nanoparticles to codeliver osteogenic gene and drug for enhanced osteodifferentiation. ACS Biomater Sci Eng 5(2), 710-723 (2019). https://doi.org/10.1021/acsbiomaterials.8b01110

165. X. Li, L. Pan, J. Shi, Nuclear-targeting MSNs-based drug delivery system: global gene expression analysis on the MDR-overcoming mechanisms. Adv Healthc Mater 4(17), 2641-2648 (2015). https://doi.org/10.1002/adhm.201500548

166. S. Biswas, N.S. Dodwadkar, P.P. Deshpande, V.P. Torchilin, Liposomes loaded with paclitaxel and modified with novel triphenylphosphonium-PEG-PE conjugate possess low toxicity, target mitochondria and demonstrate enhanced antitumor effects in vitro and in vivo. J. Control. Release 159(3), 393-402 (2012). https://doi.org/10.1016/j.jconrel.2012.01.009

167. Z. Li, K. Dong, S. Huang, E. Ju, Z. Liu, M. Yin, J. Ren, X. Qu, A smart nanoassembly for multistage targeted drug delivery and magnetic resonance imaging. Adv. Funct. Mater. 24(23), 36123620 (2014). https://doi.org/10.1002/adfm.201303662

168. L. Pan, J. Liu, Q. He, J. Shi, MSN-mediated sequential vascularto-cell nuclear-targeted drug delivery for efficient tumor regression. Adv. Mater. 26(39), 6742-6748 (2014). https://doi.org/10. 1002/adma.201402752

169. S. Naz, M. Wang, Y. Han, B. Hu, L. Teng, J. Zhou, H. Zhang, J. Chen, Enzyme-responsive mesoporous silica nanoparticles for tumor cells and mitochondria multistage-targeted drug delivery. Int. J. Nanomedicine 14, 2533-2542 (2019). https://doi.org/10.2147/ IJN.S202210

170. Y. Liu, Q. Chen, M. Xu, G. Guan, W. Hu, Y. Liang, X. Zhao, M. Qiao, D. Chen, H. Liu, Single peptide ligand-functionalized uniform hollow mesoporous silica nanoparticles achieving dualtargeting drug delivery to tumor cells and angiogenic blood vessel cells. Int. J. Nanomedicine 10, 1855-1867 (2015). https://doi.org/ 10.2147/IJN.S75098

171. L. Xiong, X. Du, F. Kleitz, S.Z. Qiao, Cancer-cell-specific nuclear-targeted drug delivery by dual-ligand-modified mesoporous silica nanoparticles. Small 11(44), 5919-5926 (2015). https://doi.org/10.1002/smll.201501056 